\title{
Recent Advances in the Clinical Value and Potential of Dexmedetomidine
}

\author{
Xiaotian Liu \\ Yueqin $\mathrm{Li}$ \\ Li Kang \\ Qian Wang
}

Department of Anesthesiology, Children's Hospital of Soochow University, Suzhou, Jiangsu, People's Republic of China
Correspondence: Qian Wang

Tel +86 05 I2-8069|3 I5

Email q_wang0302@suda.edu.cn

\begin{abstract}
Dexmedetomidine, a highly selective $\alpha 2$-adrenoceptor agonist, has sedative, anxiolytic, analgesic, sympatholytic, and opioid-sparing properties and induces a unique sedative response which shows an easy transition from sleep to wakefulness, thus allowing a patient to be cooperative and communicative when stimulated. Recent studies indicate several emerging clinical applications via different routes. We review recent data on dexmedetomidine studies, particularly exploring the varying routes of administration, experimental implications, clinical effects, and comparative advantages over other drugs. A search was conducted on the PubMed and Web of Science libraries for recent studies using different combinations of the words "dexmedetomidine", "route of administration", and pharmacological effect. The current routes, pharmacological effects, and application categories of dexmedetomidine are presented. It functions by stimulating pre- and post-synaptic $\alpha 2-$ adrenoreceptors within the central nervous system, leading to hyperpolarization of noradrenergic neurons, induction of an inhibitory feedback loop, and reduction of norepinephrine secretion, causing a sympatholytic effect, in addition to its anti-inflammation, sleep induction, bowel recovery, and sore throat reduction effects. Compared with similar $\alpha 2$-adrenoceptor agonists, dexmedetomidine has both pharmacodynamics advantage of a significantly greater $\alpha 2: \alpha 1$-adrenoceptor affinity ratio and a pharmacokinetic advantage of having a significantly shorter elimination half-life. In its clinical application, dexmedetomidine has been reported to present a significant number of benefits including safe sedation for various surgical interventions, improvement of intraoperative and postoperative analgesia, sedation for compromised airways without respiratory depression, nephroprotection and stability of hypotensive hemodynamics, reduction of postoperative nausea and vomiting and postoperative shivering incidence, and decrease of intraoperative blood loss. Although the clinical application of dexmedetomidine is promising, it is still limited and further research is required to enhance understanding of its pharmacological properties, patient selection, dosage, and adverse effects.
\end{abstract}

Keywords: dexmedetomidine, anesthesia, analgesic, sedation, surgery, anti-inflammation

\section{Introduction}

Dexmedetomidine is an anxiolytic, sedative, and pain medication. It is notable for its ability to provide sedation without risk of respiratory depression as compared to other commonly used drugs such as fentanyl and propofol and can provide cooperative or semi-rousable sedation. As a sympatholytic drug, dexmedetomidine functions as an agonist of $\alpha 2$-adrenergic receptors in certain parts of the brain. ${ }^{1,2}$ Although it was initially approved for intravenous use for up to 24 hours in the adult intensive care unit population only, its applications in clinical practice have been broadened over the past few years. Procedural sedation with dexmedetomidine 
was additionally approved by the US Food and Drug Administration in 2003 and it has appeared useful in multiple off-label applications including pediatric sedation, oral or intranasal administration, and use as an adjuvant to local analgesia/anesthetic techniques. ${ }^{3-7}$ Dexmedetomidine can reduce postoperative delirium incidence, a relatively common and serious complication in surgical patients where there is a temporary mental state characterized by confusion, incoherent speech, anxiety, and hallucinations. ${ }^{8,9}$

The many favorable physiological effects of dexmedetomidine have resulted in its increasing popularity and application, generating a lot of preclinical and clinical studies over the past few years. These studies have featured its administration through several routes including intravenous, intrathecal, intranasal, intramuscular, inhalational, and oral, as well as in procedural and surgical sedations. Considering the progressive and dynamic nature of research, constantly examining updates and advances made in an important field such as dexmedetomidine application is of high importance, especially, a well-integrated overview that captures latest data on the subject. This paper examines current data on both experimental and clinical values of dexmedetomidine, and in relation to comparative studies with similar agents. Using different combinations of the words "dexmedetomidine", "route of administration", "application", and pharmacological effect, a search was conducted on the PubMed and Web of Science libraries for recent studies, particularly, within the past five years.

\section{Overview of Dexmedetomidine}

As a highly selective a2 adrenergic receptor agonist, dexmedetomidine possesses several desirable properties including exhibiting an opioid analgesic and anesthetic sparing effect, central sympatholytic influence, arousable sedation mimicking natural sleep, and cardiovascular stabilizing abilities. Dexmedetomidine acts on the locus coeruleus to produce dose-dependent sedation with only modest hemodynamic effect and no respiratory depression. ${ }^{10-12}$ It is approved for procedural sedation with many off-label indications for which it is employed in perioperative medicine. It is also approved by the European Medicines Agency since 2017 for sedation and analgesia. ${ }^{1}$ Dexmedetomidine exhibits its hypnotic effects through stimulation of central pre-and postsynaptic $\alpha 2$-receptors in the locus coeruleus, leading to the induction of a state of unconsciousness similar to natural sleep, with a unique phenomenon that patients remain easily rousable and cooperative. The drug is rapidly distributed and is mainly hepatically metabolized into inactive metabolites by hydroxylation and glucuronidation. ${ }^{6,7}$ Dexmedetomidine possesses several admirable properties including its effectiveness in reducing delirium without depressing respiration. Notwithstanding, hemodynamic effects such as transient hypertension, bradycardia, and hypotension, result from its peripheral vasoconstrictive and sympatholytic properties. ${ }^{6}$

\section{Application in Intensive Care}

Clinical studies have shown that dexmedetomidine is suitable for both short- and long-term sedation in an intensive care setting, and is associated with a shorter time to extubation, shorter duration of mechanical ventilation, as well as patients being easier to rouse, more co-operative, and better able to communicate than those receiving midazolam or propofol. ${ }^{13}$ Other randomized, controlled trials also report that patients treated with dexmedetomidine are less likely to experience delirium compared to patients treated with propofol, midazolam, or remifentanil, and have more delirium- and coma-free days than patients receiving lorazepam. ${ }^{13-15}$ It is also associated with a decrease in the length of intensive care unit stay. ${ }^{16}$ Concerning patients aged over 65 years who are admitted to the intensive care unit after non-cardiac surgery, a study observed that prophylactic low-dose dexmedetomidine significantly reduces the incidence of delirium during the first 7 days after surgery. ${ }^{17}$ In critically ill patients with septic shock, a recent clinical trial reports that on multivariable-adjusted analysis of data obtained, dexmedetomidine appeared to be associated with lower vasopressor requirements to maintain the target mean arterial pressure (MAP) compared to usual care. ${ }^{18}$ Continuous infusion of dexmedetomidine is increasingly employed for sedation in critically ill pediatric patients too, ${ }^{19}$ where its safety profile and efficacy in reducing the incidence of withdrawal syndrome during weaning from analgosedation drugs in the pediatric intensive care unit are under clinical trial investigation. $^{20}$

\section{Application in Pediatrics/Children}

Just as observed in adults, dexmedetomidine has shown useful in diverse areas in pediatric anesthesia where its sedative properties are useful for premedication, ${ }^{21}$ fiberoptic intubation, ${ }^{22}$ and radiologic procedures. ${ }^{23}$ Its use as an adjunct for balanced anesthesia where it could decrease the use of other drugs, reduce emergence delirium, postoperative shivering, and vomiting, and exhibit neuroprotective 
effects. $^{22,24}$ Dexmedetomidine is an effective sedative for infants and children that only minimally depresses the respiratory system while maintaining a patent airway. Regardless, dexmedetomidine may depress the cardiovascular system, specifically, bradycardia, hypotension, and hypertension occur to varying degrees depending on the age of the child. ${ }^{25}$ Overall, the safety record of dexmedetomidine suggests an effective and safe use in pediatrics/children, with appropriate monitoring and interventions to manage cardiovascular sequelae.

\section{Route of Administration}

Currently, dexmedetomidine is only approved for use in humans as intravenous medication. However, several studies have explored the practical potentials of using it through other routes. Some of the documented routes of dexmedetomidine administration that have gained traction include intrathecal, intranasal, oral, intramuscular, and inhalational (Figure 1).

\section{Intravenous}

The initial approval of dexmedetomidine was for intravenous use for up to 24 hours in adults in the intensive care unit. The intravenous route of administration remains a common application route. In its general application, intravenous dexmedetomidine bolus is administered over 10 minutes (loading dose), followed by continuous infusion for maintenance (maintenance infusion) to prevent hemodynamic changes. ${ }^{26} \mathrm{~A}$ decrease in heart rate up to $30 \%$ from baseline until 30 beats $/ \mathrm{min}$ after $0.5 \mathrm{mcg} / \mathrm{kg}$ initial dose over $10 \mathrm{~min}$ has been reported. ${ }^{25}$ In specific applications, intravenous dexmedetomidine with its stable cardio-respiratory profile, better sedation, overall patient satisfaction, and analgesia could be a valuable adjunct for intraoperative sedation during spinal anesthesia. ${ }^{27}$ Approximately 55\% of patients undergoing cesarean delivery under epidural or spinal anesthesia experience shivering, which may interfere with the monitoring of vital signs. Recent studies have shown that intravenous dexmedetomidine potentially helps to alleviate shivering associated with anesthesia. $^{28,29}$ One of these clinical trial studies observed that a single intravenous bolus of dexmedetomidine decreased the duration of shivering for up to 15 min during cesarean delivery under neuraxial anesthesia. $^{29}$ Others have observed that the administration of dexmedetomidine as a slow intravenous bolus of $15-30 \mathrm{mg}$ in this setting, is as or more effective than $25 \mathrm{mg}$ intravenous meperidine; it works within 45-90 s and the patient would rarely require a second dose. Intravenous dexmedetomidine provides an avenue for reducing shivering during cesarean delivery, limiting opioid exposure in patients, and possible replacement of drugs like meperidine. ${ }^{30}$

\section{Intrathecal}

Clinical studies have evaluated the effect of intrathecal dexmedetomidine on the duration of postoperative analgesia, postoperative pain scores, and incidences of adverse events. In a systematic review and meta-analysis of randomized controlled trials, the authors concluded that intrathecal administration of dexmedetomidine prolongs postoperative analgesia duration, decreases 24-hr pain

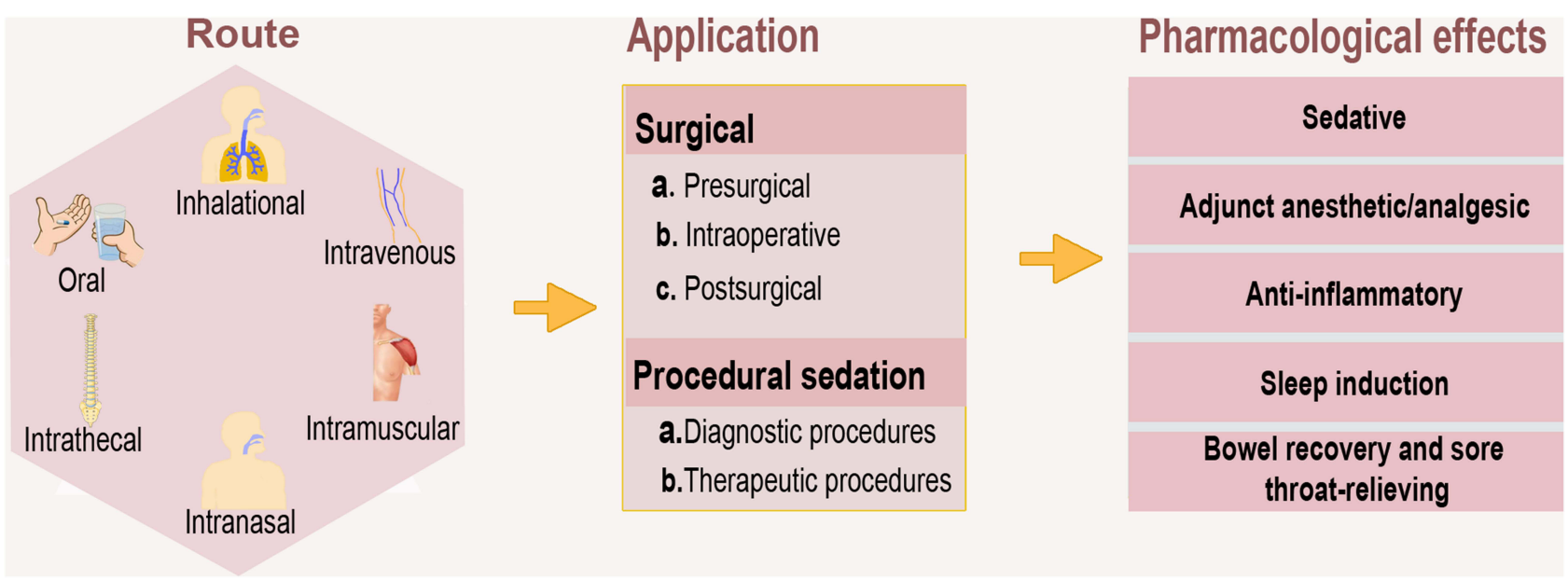

Figure I Routes, procedures, and pharmacological effects of dexmedetomidine. In addition to the intravenous administration of dexmedetomidine, it equally produces sufficient pharmacological outcome through other routes of administration in both surgical and procedural sedation. In its application, dexmedetomidine functions as a sedative, analgesic, adjunct anesthetic/analgesic, and anti-inflammatory agent, among other desirable effects such as bowel recovery and sore throat relief. 
intensity, and decreases the incidence of shivering without an increase in other adverse events. ${ }^{31}$ Intrathecal dexmedetomidine increases the duration of the sensory blockade and analgesic effects and decreases the consumption of postoperative rescued sufentanil, an opioid analgesic associated with risks of addiction, abuse, and misuse that can lead to overdose and death. ${ }^{32}$ The analgesic role of intrathecal dexmedetomidine is promising, owing to its capability to significantly increase postoperative analgesia duration. Its application could be considered for patients undergoing surgeries with significant postoperative pain, and particularly in patients who are intolerant of systemic analgesia. Notwithstanding, the optimum dose for various surgeries and its long-term neurological impacts warrants further assessment. In a comparative study of subarachnoid anesthesia that is supplemented with either intrathecal or intravenous dexmedetomidine, it was observed that although the onset of sensory and motor block was similar in both groups, there was a longer duration in motor recovery and two-segment sensory regression in the intrathecal group. In effect, intrathecal dexmedetomidine prolongs the influence of anesthesia with arousable sedation as compared with intravenous dexmedetomidine. ${ }^{33}$

\section{Intranasal}

Intranasal administration of dexmedetomidine produces safe and effective sedation in both adults and children. Intranasal dexmedetomidine may be given via drops from a syringe or by nasal mucosal atomization, a safe and painless way of delivering atomized medication with rapid absorption across mucosal membranes to the patient's bloodstream. ${ }^{12,34}$ While $1 \mu \mathrm{g} . \mathrm{kg}(-1)$ intranasal dexmedetomidine produces significant sedation in children aged 2-12 years, the median $(95 \% \mathrm{CI})$ time for onset of sedation is estimated to be $25(25-30)$ min and the median duration of sedation is $85(55-100) \mathrm{min}^{35}$ It is reported that although intravenous dexmedetomidine administration has a significantly faster onset compared to intranasal administration, there is no significant difference in sedation duration across these treatment routes. Moreover, there is no significant difference in the median onset time between intranasal routes by the atomizer and by drops. $^{12}$ Intranasal dexmedetomidine has been used successfully for sedation in children. A study that compared the two methods of intranasal dexmedetomidine delivery among 279 children reports that the successful sedation rate was $82.5 \%$ and $84.5 \%$ for atomizer and drops, respectively, with less sedation success in older children. ${ }^{34}$ This implies that both modes of intranasal dexmedetomidine administration are equally effective, although increasing the age of children is linked with a reduced likelihood of successful sedation. In a similar study in pediatric patients aged 2-5 years, the researcher observed comparable onset time between both methods, with no patient requiring clinical intervene in heart rate reduction and none suffering respiratory depression after administrations of dexmedetomidine. Notwithstanding, the faces, legs, activity, cry, and consolability (FLACC) score was reduced in the mucosal atomization device group compared to the drops group, implicating nasal mucosal atomization as a better option in reducing responses to venous cannulation in pediatrics. $^{36}$

\section{Oral}

An oral formulation of dexmedetomidine may broaden its use and benefits in numerous care settings. A pharmacokinetic and pharmacodynamic study of oral dexmedetomidine in healthy volunteers reports that its oral administration is associated with plasma concentrationdependent decreases in heart rate and mean arterial pressure. However, only $700-\mathrm{mcg}$ (but not $300 \mathrm{mcg}$ or 500 $\mathrm{mcg}$ ) reached plasma concentrations that have previously been associated with sedation. ${ }^{10}$ Another study investigated the effect of a capsule-based solid oral dosage formulation of dexmedetomidine on sleep polysomnography. In this single-site, placebo-controlled, randomized, crossover, double-blind Phase II clinical trial study, oral dexmedetomidine increased the duration of non-rapid eye movement (non-REM) stage 2 sleep by $63 \mathrm{~min}$ and decreased the duration of rapid eye movement (REM) sleep by 42 min. $^{37}$ Many studies have also compared oral dexmedetomidine with the most popular oral premedication in children, midazolam, due to the favorable clinical profile and suitability of dexmedetomidine as an alternative to midazolam. Sajid and colleagues noted that premedication with oral dexmedetomidine is as effective as oral midazolam in providing sedation and anxiolysis in children. Moreover, dexmedetomidine in addition reduces the incidence and severity of emergence agitation. ${ }^{38}$ Similar observations have been documented including oral dexmedetomidine providing satisfactory sedation levels, ease of parental separation, and mask acceptance in children in a manner similar to midazolam, with children premedicated with dexmedetomidine experiencing lesser emergence delirium than those premedicated with midazolam. $^{39-41}$ 


\section{Intramuscular}

Dexmedetomidine has been administered to adults by intramuscular injection for perioperative anxiolysis and sedation. ${ }^{42}$ Several initial studies reported intramuscular route is an alternative approach to dexmedetomidine delivery for pediatric sedation and called for larger studies to evaluate the safety, efficacy, and hemodynamic outcome associated with the intramuscular dexmedetomidine in the care of patients. ${ }^{42-44}$ Intramuscular dexmedetomidine could be applied in pediatric sedation without requiring intravenous access and has merits for electroencephalography via stimulating natural sleep pathway; however, only a limited number of studies have been documented on the efficacy of intramuscular dexmedetomidine. Recent research noted that Intramuscular dexmedetomidine exhibits a higher sedation success rate and shorter time to achieve the desired sedation level compared with oral chloral hydrate; thus, it may be an effective alternative for oral chloral hydrate in pediatric patients requiring sedation for electroencephalography. ${ }^{45}$ Children with autism spectrum disorders requiring procedural sedation may represent a challenge for pediatricians and anesthesiologists in the emergency setting due to limited communication and poorly predictable behavioral skills. Interestingly, a case series report of children with autism spectrum disorders treated with intramuscular dexmedetomidine to perform urgent painless diagnostic procedures in various health facilities indicates that this route of administration is feasible for these special children needing urgent procedural sedation. ${ }^{46}$ There is also evidence that dexmedetomidine premedication in low dose $(1 \mu \mathrm{g} \cdot \mathrm{kg}-1)$ by intramuscular route effectively induces preoperative sedation and adjuvant anesthetic effect without clinically significant bradycardia or hypotension. ${ }^{43}$

\section{Inhalational}

Recent studies have examined the effects of dexmedetomidine administration through a nebulized route. For example, Misra et al evaluated the effects of preoperative dexmedetomidine nebulization on the hemodynamic response to laryngoscopy and intubation and examined the intraoperative anesthetic-analgesic requirements and recovery outcomes. The authors concluded that nebulized dexmedetomidine at $1 \mu \mathrm{g} / \mathrm{kg}$ attenuated the increase in heart rate but not systolic blood pressure, following laryngoscopy and reduced the intraoperative anesthetic and analgesic consumption, thus a probable alternative to the intravenous route in short duration surgeries. ${ }^{47}$ In a similar study, nebulized dexmedetomidine was evaluated as a premedication in blunting the hemodynamic response to laryngoscopy and tracheal intubation. It was found that inhalation of the drug effectively blunted the stress response to laryngoscopy and intubation with no adverse effects. ${ }^{48}$ These promising outcomes provide an avenue for further exploration of the inhalational administration of dexmedetomidine.

\section{Experimental Value}

Literature reports a variety of animal model studies that are linked with possible translation in clinical medicine. Key observations and clinical application value of some of these studies are summarized in Table 1. Among the many experimental models of human diseases that have shown the promising application of dexmedetomidine include lipopolysaccharide-induced acute lung injury models, ${ }^{49,50}$ myocardial, ${ }^{51}$ lung, ${ }^{52}$ and intestinal ${ }^{53}$ ischemia-reperfusion injury models, caeca ligation, and puncture models, ${ }^{54-56}$ brain in vitro and in vivo models of sepsis, ${ }^{57}$ a murine model of traumatic brain injury, ${ }^{58}$ and spinal cord injury. ${ }^{59}$ For instance, treatment with dexmedetomidine in experimental sepsis models reduces cytokine transcription, mortality, sepsis-associated heart injury, and inhibits inflammation, rendering it beneficial during septic conditions. ${ }^{60}$

Dexmedetomidine appears to have a protective role for the heart, liver, and spleen, as well as a beneficial role for the function of lungs and kidneys as it reduces sepsisinduced injuries and apoptosis in intra-abdominal experimental sepsis models. ${ }^{61-63}$ Sepsis is a frequent antecedent of lung injury characterized by mitochondrial dysfunction, where the functional integrity of cells is influenced by mitochondrial dynamics. Interestingly, dexmedetomidine protects mice against cecal ligation and puncture-induced lung injury by mitigating changes in mitochondrial fusion and fission. ${ }^{56}$ This consequently prevents changes in the wet/dry weight ratio and oxygenation index in mice, decreases markers of oxidative stress and pro-inflammatory mediators, and ameliorates altered activity of caspase8 , caspase- 3 , and caspase- 9 enzyme in the lung tissue. ${ }^{56}$ Moreover, dexmedetomidine prevents endotoxin-induced acute lung injury in vivo and in vitro through the preservation of mitochondrial dynamic equilibrium via the hypoxia-inducible factor (HIF)-1a/Heme oxygenase (HO)-1 signaling pathway ${ }^{64}$ and mitigates lipopolysaccharide-induced acute lung injury by abrogating oxidative stress, mitochondrial dysfunction, and apoptosis in rats 
Table I Summary of Preclinical Studies Involving Dexmedetomidine and Their Clinical Implications

\begin{tabular}{|c|c|c|c|}
\hline Experimental Model & Key Observations & Value in Clinical Application & Reference \\
\hline $\begin{array}{l}\text { Cecal ligation and } \\
\text { puncture-induced lung } \\
\text { injury in mice }\end{array}$ & $\begin{array}{l}\text { Dexmedetomidine significant decreases pro- } \\
\text { inflammatory mediators and markers of oxidative } \\
\text { stress in the lung tissue }\end{array}$ & $\begin{array}{l}\text { Dexmedetomidine as a promising protective agent } \\
\text { in lung injury }\end{array}$ & [56] \\
\hline $\begin{array}{l}\text { Spatial learning and } \\
\text { memory in neonatal } \\
\text { rats }\end{array}$ & $\begin{array}{l}\text { Neonatal injection of dexmedetomidine }(20 \mu g / \\
\mathrm{kg}) \text { enhances spatial learning and memory. }\end{array}$ & $\begin{array}{l}\text { Dexmedetomidine as a neuroprotective agent in } \\
\text { brain injury }\end{array}$ & [70] \\
\hline $\begin{array}{l}\text { Hippocampal } \\
\text { neurogenesis in mice }\end{array}$ & $\begin{array}{l}\text { Dexmedetomidine attenuates ethanol-mediated } \\
\text { hippocampal neurogenesis and reverses induced- } \\
\text { neuroinflammation }\end{array}$ & $\begin{array}{l}\text { Dexmedetomidine could reverse neurotoxicity in } \\
\text { the developing hippocampus and deficits in } \\
\text { hippocampal neurogenesis. }\end{array}$ & [72] \\
\hline $\begin{array}{l}\text { Acute lung and kidney } \\
\text { injuries in a rat model } \\
\text { of intra-abdominal } \\
\text { sepsis }\end{array}$ & $\begin{array}{l}\text { Dexmedetomidine attenuates sepsis-induced lung } \\
\text { and kidney injuries and apoptosis }\end{array}$ & $\begin{array}{l}\text { This calls for the need for comparative studies to } \\
\text { determine the effects of dexmedetomidine on } \\
\text { organ functions in early human sepsis }\end{array}$ & [55] \\
\hline $\begin{array}{l}\text { Rat model of cervical } \\
\text { spinal cord injury }\end{array}$ & $\begin{array}{l}\text { Dexmedetomidine improves neurological } \\
\text { outcomes and decreases tissue damage after } \\
\text { spinal cord injury }\end{array}$ & $\begin{array}{l}\text { Dexmedetomidine as a promising inhibitor of } \\
\text { neuroinflammation }\end{array}$ & [59] \\
\hline $\begin{array}{l}\text { Acute kidney injury via } \\
\text { ischemia-reperfusion in } \\
\text { mice }\end{array}$ & $\begin{array}{l}\text { Dexmedetomidine mitigates pathohistological } \\
\text { changes and apoptosis in the lung via } \alpha 2 \mathrm{AR} / \mathrm{PI} 3 \mathrm{~K} / \\
\text { Akt pathway }\end{array}$ & $\begin{array}{l}\text { This demonstrates a novel protective mechanism } \\
\text { against remote lung injury, hence may be a } \\
\text { promising therapeutic avenue in remote organ } \\
\text { cross-talk }\end{array}$ & [73] \\
\hline $\begin{array}{l}\text { Cecal ligation and } \\
\text { puncture-induced liver } \\
\text { injury in mice }\end{array}$ & $\begin{array}{l}\text { Dexmedetomidine improves the survival rate of } \\
\text { septic mice at the early stage and ameliorated the } \\
\text { pathology of sepsis-induced liver injury }\end{array}$ & $\begin{array}{l}\text { Dexmedetomidine protects against liver injury by } \\
\text { enhancing autophagy, which alleviates inflammatory } \\
\text { responses }\end{array}$ & [61] \\
\hline $\begin{array}{l}\text { Cecal ligation and } \\
\text { puncture-induced heart } \\
\text { injury in mice }\end{array}$ & $\begin{array}{l}\text { Dexmedetomidine attenuates sepsis-induced } \\
\text { heme oxygenase-I overexpression and reduces } \\
\text { iron concentration and ferroptosis via enhancing } \\
\text { glutathione peroxidase } 4\end{array}$ & $\begin{array}{l}\text { Promising alleviation effect in sepsis-induced } \\
\text { myocardial cellular injury, hence good basis for } \\
\text { clinical studies }\end{array}$ & [62] \\
\hline $\begin{array}{l}\text { Cecal ligation and } \\
\text { puncture-induced sepsis } \\
\text { in rats }\end{array}$ & $\begin{array}{l}\text { Dexmedetomidine exhibits protective effects on } \\
\text { the myocardium by the induction of myocardial } \\
\text { autophagy and reduction of inflammation }\end{array}$ & $\begin{array}{l}\text { These observations provide the foundation for } \\
\text { further study and may serve as the basis for } \\
\text { innovative therapeutic strategies against septic } \\
\text { myocardial dysfunction. }\end{array}$ & [74] \\
\hline $\begin{array}{l}\text { Lung ischemia- } \\
\text { reperfusion injury in } \\
\text { rats }\end{array}$ & $\begin{array}{l}\text { Dexmedetomidine attenuates lung ischemia- } \\
\text { reperfusion injury by activating the PI3K/Akt } \\
\text { signaling pathway at the transcriptional level }\end{array}$ & $\begin{array}{l}\text { Potential application in human ischemia-reperfusion } \\
\text { induced lung injury }\end{array}$ & [52] \\
\hline $\begin{array}{l}\text { Sedation requirements } \\
\text { in an autistic rat model }\end{array}$ & $\begin{array}{l}\text { Autistic rats showed significantly longer loss of } \\
\text { righting reflex times and shorter return of righting } \\
\text { reflex times than controls }\end{array}$ & $\begin{array}{l}\text { This outcome supports the clinical observations of } \\
\text { increased anesthetic sedative requirements in } \\
\text { children with autism }\end{array}$ & [75] \\
\hline
\end{tabular}

Abbreviations: $\alpha 2 \mathrm{AR}$, alpha2-noradrenergic receptor; PI3K, phosphoinositide-3-kinase.

model. ${ }^{65}$ Dexmedetomidine pretreatment in rat model of sham operation or myocardial ischemia/reperfusion, significantly attenuates ischemia/reperfusion-induced cardiac damage, as evidenced by a reduction in short-term injury indicators such as myocardial infarct size, myocardial apoptosis, cTnI release, cardiac high mobility group box protein 1 (HMGB1) expression, TNF- $\alpha$, and IL-6 secretion, as well as long-term cardiac function improvement at 4 weeks after-reperfusion. ${ }^{66}$ Other protective mechanisms of dexmedetomidine on cardiac tissue include protection through activating the PI3K/Akt signaling, ${ }^{67}$ by downregulating the HMGB1-TLR4-MyD88-NF-кB signaling 
pathway, ${ }^{68}$ and by inhibiting inflammation and apoptosis via downregulating the endoplasmic reticulum stress signaling pathway. ${ }^{69}$

Several experimental studies have demonstrated the neuroprotective efficacy of dexmedetomidine in many neurological and brain injury models. Zhang and colleagues investigated the effect of neonatal dexmedetomidine administration in promoting hippocampal neurogenesis and improving hippocampus-dependent spatial learning and memory under physiological conditions. Results indicated that $20 \mu \mathrm{g} / \mathrm{kg}$ of dexmedetomidine improves memory and spatial learning in rat pups, probably through the promotion of synaptic plasticity and hippocampal neurogenesis via stimulation of the glial cell line-derived neurotrophic factor (GDNF)/neural cell adhesion molecule (NCAM)/cAMP response element-binding protein (CREB) signaling. ${ }^{70}$ It is reported that a single administration of dexmedetomidine on postnatal day 7 in rats preserves hippocampal synaptic plasticity as well as synaptic transmission later in adulthood. ${ }^{71}$ Ethanol exposure within a period comparable to the third trimester in humans results in obvious neurotoxicity in the developing hippocampus and persistent deficits in hippocampal neurogenesis. In the mice model, dexmedetomidine pretreatment protects against ethanol-mediated inhibition of hippocampal neurogenesis in postnatal mice and reverses ethanol-induced neuroinflammation through repression of microglia activation and the expression of inflammatory cytokines such as TNF $\alpha$, IL-6, IL-1 $\beta$, and MCP-1. ${ }^{72}$

\section{Clinical Effects}

\section{As a Sedative}

Dexmedetomidine is applied as a sedative in intensive care for both adults and children, ${ }^{13}$ in non-surgical procedures, ${ }^{40}$ and in surgical procedures. ${ }^{76}$ It is suitable for short- and long-term sedation, as well as light and deep sedation. Intranasal dexmedetomidine premedication is employed as a sedative to reduce stress and anxiety before general anesthesia in children. Systematic review and meta-analysis of randomized-controlled trials in children indicate that intranasal dexmedetomidine premedication provided more satisfactory sedation at parent separation, reduces the need for rescue analgesics, associated with a significantly lower incidence of nasal irritation and postoperative nausea and vomiting, as compared with other premedication treatments. ${ }^{77}$ Emergence agitation is one of the most frequent and intractable postoperative complications among children undergoing surgery under general anesthesia. Dexmedetomidine provides ideal sedation, reducing preoperative anxiety, and facilitating smooth induction of anesthesia, hence widely used in pediatric surgery. Meta-analysis of existing data indicates that dexmedetomidine does not only prevent emergence agitation, but also relieves postoperative pain, decreases the need for rescue analgesics, and decreases postoperative nausea and vomiting events. ${ }^{78-80}$

\section{As an Adjunct Anesthesia/Analgesic}

Dexmedetomidine has been demonstrated to function as adjunct anesthesia to enhance specific components of anesthesia, permitting lower doses of general anesthetics with fewer side effects. For instance, it has been proposed as a perineural local anesthetic adjunct to prolong peripheral nerve block duration, with new evidence indicating that it improves brachial plexus block onset, quality, and analgesia. ${ }^{81}$ Regardless, these benefits are to be weighed against elevated risks of motor block prolongation and transient bradycardia and hypotension. The favorable physiological effects combined with a limited adverse effect profile present dexmedetomidine as an attractive adjunct to anesthesia (including general and regional) for a variety of procedures in the operating room. ${ }^{4}$ Adjunct dexmedetomidine has been utilized to prolong local anesthetic actions and enhance effects in peripheral nerve blocks. ${ }^{82}$ Assessment of current evidence regarding the use of dexmedetomidine as an adjuvant to local anesthetic agents for caudal blockade anesthesia and analgesia in children indicates sufficient data to recommend its addition in patients undergoing lower extremity and infra-umbilical surgical procedures. ${ }^{83}$ Besides its effects as a sedative, sympatholytic, and analgesic, dexmedetomidine has shown beneficial in its use as an adjuvant to: enhance analgesia; regulate hemodynamic response to intubation, and pneumoperitoneum and; decrease opioid-associated adverse events. A randomized controlled study reports that intraoperative dexmedetomidine infusion as adjunct analgesia is safe and effective for improving analgesia, as evident in reducing the number of patients with severe postoperative pain, postoperative consumption of morphine, and prolong time to first use of rescue analgesia. ${ }^{84}$

\section{As an Analgesic}

Intraoperative pain management with analgesics such as remifentanil is associated with elevated postoperative analgesic requirements and opioid consumption. 
However, emerging evidence shows dexmedetomidine to possess characteristic properties that present it as promising analgesia during and after anesthesia. In postsurgical pain management, it has been reported to have a better pain response and hemodynamic stability than ropivacaine $^{85}$ and decreases intraoperative opioid consumption with improved postoperative sleep quality. ${ }^{86}$ In a systematic review and meta-analysis of postoperative pain, general anesthesia including dexmedetomidine exhibited lower pain scores at rest at two (primary outcome) and 24 (secondary outcomes) postoperative hours, with less use of postoperative morphine and rescue analgesia compared to remifentanil. ${ }^{87}$ This shows some level of evidence of intraoperative dexmedetomidine during general anesthesia to improve pain outcome during the first 24 postoperative hours compared to remifentanil. Intraoperative dexmedetomidine infusion is effective and safe for enhancing analgesia during and after elective laparoscopic cholecystectomy, where it appears to significantly decrease the number of patients with severe postoperative pain, postoperative consumption of morphine, and prolong time to first use of rescue analgesia. ${ }^{84}$ Another study concluded that postoperative patient-controlled analgesia strategies with opioid-demedetomidine combinations reduce postoperative pain, opioid requirement, and opioid-related adverse events, implicating dexmedetomidine as a useful adjuvant to opioid-based patientcontrolled analgesia. ${ }^{88}$ However, a recent clinical trial asserted that balanced opioid-free anesthesia with dexmedetomidine, compared with remifentanil, does not produce fewer postoperative opioid-related adverse events, but rather causes a greater incidence of serious adverse events, especially bradycardia and hypoxemia. ${ }^{89}$

\section{As an Anti-Inflammatory Agent}

Most animals have demonstrated the reduction effect of dexmedetomidine on serum and/or tissue inflammatory mediators such as TNF $\alpha$, IL-6, IL-1 $\beta$, NF- $\kappa \mathrm{B}$ (nuclear factor kappa light chain enhancer of activated B cells), and TLR4 (toll-like receptor 4), among others. ${ }^{90-92}$ Many of these findings have been confirmed in human studies, where dexmedetomidine is reported to reduce C-reactive protein (CRP), TNF $\alpha$, IL-6, IL-1 $\beta$, and alters several other mediators. $^{93-95}$ For instance, dexmedetomidine inhibits inflammatory response and reduces immunosuppression in patients undergoing multilevel spinal fusion, ${ }^{95}$ prevents renal ischemia-reperfusion injury in part via cholinergic anti-inflammatory mechanisms, ${ }^{91,96}$ and plays an immunomodulatory role in shifting the T-helper (Th)1/ Th2 cytokine balance toward Th1 in patients with anesthetic and surgical related stress. ${ }^{97,98}$ Dexmedetomidine exerts anti-inflammatory effects in many neurological conditions by reducing neuroinflammation. A recent study documents that dexmedetomidine upregulates microglial anti-inflammatory (M2) polarization status through inhibition of the phosphorylation of ERK1/2, resulting in enhanced anti-inflammatory effects in BV2 cells. ${ }^{99}$ Other mechanisms associated with the anti-inflammatory effect of dexmedetomidine on microglia include reduction of the expression of microglia inflammatory (M1) marker genes such as tumor necrosis factor (TNF)- $\alpha$, interleukin-1 $\beta$ (IL$1 \beta$ ), and IL- 6 but improving the expression of M2 markers such as arginase-1 (Arg-1) and Flt3-interacting zinc finger protein 1 (Fizz-1), ${ }^{100}$ and attenuation of inducible nitric oxide synthase (iNOS) and nitric oxide (NO) via inhibition of extracellular signal-regulated kinase (ERK) activation in both BV2 cells and primary microglial cells. ${ }^{101}$ The overview of the anti-inflammatory effect of dexmedetomidine is presented in Figure 2.

\section{As a New Class of Sleep-Enhancing Medication}

Sleep, which consists of rapid eye movement (REM) and non-REM stages 1-3 (N1-N3), is a naturally occurring state of reduced arousal that is critical for normal cardiovascular, immune, and cognitive functions. Pharmacological induction of altered arousal states that neurophysiologically approximate natural sleep, known as biomimetic sleep, might eliminate drug-induced neurocognitive dysfunction. Scientists have explored the application of dexmedetomidine as a sleep enhancer with promising outcomes. ${ }^{10,37}$ Akeju and colleagues report that pharmacological induction of biomimetic N3 sleep with psychomotor sparing benefits is feasible, and suggest that $\alpha 2$ a-adrenergic agonists might be developed as a new class of sleep-enhancing medications with neurocognitive sparing benefits. ${ }^{102}$ A recent systematic review showed that dexmedetomidine has advantages in improving patients' postoperative sleep quality. ${ }^{103}$ Other studies have also assessed the feasibility of patient-controlled sleep with dexmedetomidine in treating chronic intractable insomnia. Patient-controlled analgesia (PCA) is an "ondemand" system that allows patients to self-administer intravenous medications in small bolus doses. A PCA study concluded that patient-controlled sleep with 


\section{Microglia}

M2 Microglia

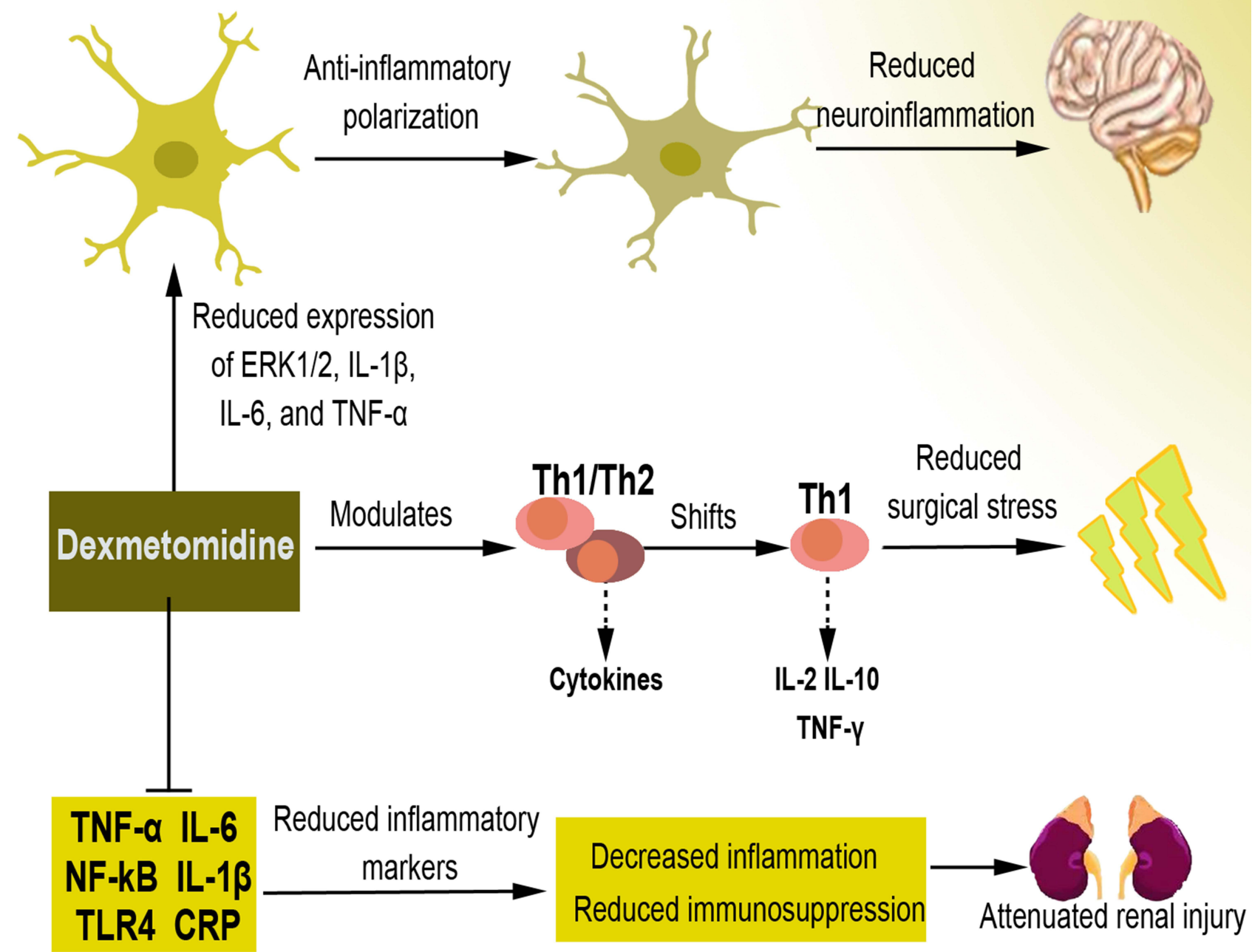

Figure 2 The anti-inflammatory effect of dexmedetomidine. Some of the specific mechanisms through which dexmedetomidine reduces inflammation include the inhibited expression of ERKI/2, ILI $\beta$, IL6, and TNF, resulting in the polarization of microglia into M2 phenotype and reducing neuroinflammation. Dexmedetomidine also regulates ThI/Th2 cells and their cytokines towards ThI shift, which causes reduced surgical stress. Moreover, it inhibits inflammatory markers, leading to downregulated immunosuppression capable of mitigating renal injury.

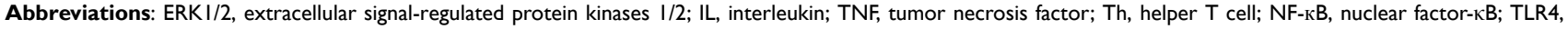
toll-like receptor 4; CRP, C-reactive protein.

dexmedetomidine might be a potential treatment for patients with chronic intractable insomnia; however, it is an off-label use, and the potential side effects of dexmedetomidine with long-term use needs further evaluation. ${ }^{104}$

\section{Bowel Recovery and Sore Throat- Relieving Effects}

Recently, a number of studies have explored the effect of dexmedetomidine on postoperative bowel recovery parameters such as time to first bowel sounds, first faces, first flatus, or time to oral diet. A systematic review and metaanalysis of randomized controlled trials concluded that the perioperative administration of dexmedetomidine in adult patients receiving general anesthesia remarkedly shortens the time to first flatus, faces, and composite bowel recovery but does not result in a shorter time to oral diet. ${ }^{105}$ In a randomized controlled trial of patients who underwent laparoscopic nephrectomy, the postoperative infusion of dexmedetomidine at $0.04 \mu \mathrm{g} / \mathrm{kg} / \mathrm{h}$ facilitated bowel movements, as times to first flatus, defecation, and eating were significantly shorter. ${ }^{106}$ Moreover, the combination of lidocaine and dexmedetomidine infusion significantly enhanced postoperative recovery of bowel function and pain relief in patients undergoing abdominal hysterectomy. ${ }^{107}$ These 
findings indicate that both the postoperative and perioperative administration of the drug improves bowel recovery function, thus the need to further explore the optimum condition to maximize effect, including dosage and route.

Postoperative sore throat is an undesirable intubationrelated complication after surgery. Several studies have examined the effects of dexmedetomidine in preventing this occurrence. Liu et al report that perioperative intravenous administration of dexmedetomidine has a positive effect on preventing sore throat. ${ }^{108}$ Several other studies have indicated the ability of dexmedetomidine to prevent or reduce the incidence and severity intubation-related sore throat, ${ }^{109}$ including intraoperative infusion, ${ }^{110}$ and preoperative nebulization. ${ }^{111}$

\section{Key Surgical Applications Neurosurgery and Neurosurgical \\ Procedures}

Dexmedetomidine stimulates an arousable state of sedation, a beneficial effect in neurosurgical procedures that requires the patient to cooperate with procedures such as tumor surgery or implantation of deep brain stimulators. During neurosurgical procedures that require monitoring of somatosensory- and/or motor-evoked potentials, dexmedetomidine could be employed as an adjunct to general anesthesia with GABAergic drugs to reduce the dosage of the latter when these drugs impair the monitoring signals. ${ }^{1,112}$ The use of dexmedetomidine has also been associated with neuroprotective effects and a decreased incidence of delirium, but studies confirming these effects in perioperative neurosurgical settings are lacking.

Deep brain stimulation (DBS) electrode implantation is a common treatment procedure for Parkinson's Disease, various dystonias, medication-resistant Tourette's syndrome, and a likely more frequent future treatment option for obsessive-compulsive disorders, depression, and obesity. The application of dexmedetomidine in DBS surgery presents more advantages over benzodiazepines and propofol. ${ }^{113-116}$ Dexmedetomidine appears to exert only modest effects on the brain's electrophysiological properties such as firing rates, and recording amplitudes, although these effects might be dependent on the dosage, method of administration, and location of recordings. ${ }^{117,118}$ A review article in this area of dexmedetomidine application concluded that its use in managing conditions, including Parkinson's disease during unilateral deep brain stimulation of the subthalamic nucleus (STN) is safe and effective and could be considered a promising option for sedation during this type of procedure. ${ }^{119}$

Other areas of neurological procedures that are gaining increased application of dexmedetomidine are awake craniotomy ${ }^{120,121}$ and awake fiberoptic intubation. ${ }^{122,123}$ The goal of awake craniotomy is to maintain adequate sedation, analgesia, respiratory, and hemodynamic stability and also to provide a cooperative patient for neurologic testing. The use of dexmedetomidine infusion with regional scalp block in patients undergoing awake craniotomy appears safe and efficacious, with the absence of major complications and higher patient satisfaction score, making it close to an ideal agent for craniotomy in an awake state. ${ }^{124,125}$ Moreover, a combination of local anesthesia without scalp block, low-dose infusion of dexmedetomidine, propofol, and remifentanil, without the need for airways management was found to present the advantage of decreasing the dose of each drug and thus reducing the occurrence of side effects, exhibiting smooth and rapid awakenings of patients, and keeping the brain relaxed during the entire procedure. ${ }^{126}$ Both intravenous and local application of dexmedetomidine during awake fiberoptic intubation appears promising, decreasing sudden changes in hemodynamic values and coughing, and improving patient tolerance and intubation scores. ${ }^{127,128}$

\section{Cardiac Surgery}

The safety and efficacy of dexmedetomidine in patients who undergo cardiac surgery have been reported in several studies. In clinical studies, its application in cardiac surgery results in a reduced time of surgery and stay in intensive care units, reduced risks of abnormal hemodynamics, and improved delirium with overall good safety outcomes. ${ }^{2}$ In older patients undergoing cardiac surgery, postoperative scheduled intravenous acetaminophen, combined with intravenous dexmedetomidine or propofol, reduces in-hospital delirium compared to placebo. ${ }^{129}$ Similarly, in pediatric patients undergoing cardiac surgery, the continuous intraoperative infusions of dexmedetomidine reduce sevoflurane requirements and decrease the incidence of emergence delirium, which is associated with decreased plasma melatonin levels and surgical stress. ${ }^{130}$ When compared with propofol, dexmedetomidine sedation reduces incidence, delays onset, and shortens the duration of postoperative delirium in patients after cardiac surgery. ${ }^{131}$ Other studies have also noted that although dexmedetomidine could decrease postoperative delirium and is associated with a shorter length of 
intubation after cardiac surgery, it might increase bradycardia compared to propofol. ${ }^{132}$ On the other hand, a 2013-2018 trial published in The Lancet reports that dexmedetomidine infusion, initiated at anesthetic induction and continued for 24 hours, did not reduce postoperative atrial arrhythmias or delirium in patients recovering from cardiac surgery. ${ }^{133}$ Another clinical trial observed that the addition of low-dose-rate dexmedetomidine to a sedative regimen based on propofol does not result in a different risk of in-hospital delirium in older patients undergoing cardiac surgery, concluding that in the phase of both benefit and harm in secondary outcomes, the supplementation of postoperative propofol with dexmedetomidine is not recommended. ${ }^{134}$ These apparent contradictions call for further clinical trial studies to establish concrete evidence on these outcomes.

\section{Cesarean Section}

Studies show that dexmedetomidine as supplements to anesthetics results in improved quality of the anesthesia and reduces the anesthetic agent requirement for cesarean section. ${ }^{135}$ Dexmedetomidine, as an adjuvant, has been reported to prolong the duration of spinal analgesia when added to local anesthetic. Intrathecal $5 \mu \mathrm{g}$ dexmedetomidine improves the efficacy of spinal bupivacaine by $24 \%$ in patients undergoing cesarean section with spinal anesthesia, with no additional adverse event observed by adding spinal dexmedetomidine. ${ }^{136}$ Shivering is among the common troublesome complications of spinal anesthesia and causes discomfort and discontentment in parturients undergoing cesarean sections. The administration of intrathecal dexmedetomidine is effective in lowering the intensity and incidence of shivering in women in labor undergoing cesarean sections under spinal anesthesia, without major adverse effects. ${ }^{137}$ It is also reported that dexmedetomidine exerts protective effects on kidney injury of parturients with preeclampsia undergoing cesarean section. ${ }^{138}$ An assessment of its effect on both the mothers and neonates during cesarean section under general anesthesia indicates that dexmedetomidine presents better neonatal Apgar scores, postoperative analgesia, and decreased catecholamine release. ${ }^{139}$ Moreover, the use of dexmedetomidine in the perioperative period of cesarean section is not only conducive to the early conversion of infant feeding to exclusive breastfeeding but can also enhance the recovery quality and comfort of the parturient, optimize analgesia, reduce the time to the first lactation, and increase lactation. ${ }^{140}$

\section{Cancer Surgery}

Surgery is considered the best curative option for several malignancies. Notwithstanding, the use of anesthesia and the surgical procedure itself are associated with immunosuppression and stress, which could contribute to immune escape of residual tumor cells and cancer recurrence. ${ }^{141,142}$ Over the past years, researchers have been exploring concrete evidence concerning the possibility of anesthesia playing a significant role in tumor recurrence and metastasis. Just like other anesthetic agents, data from animal studies have pointed towards a potential role of dexmedetomidine in promoting cancer metastasis and recurrence when used perioperatively, especially in breast cancer surgeries, likely due to the presence of $\alpha 2$ adrenoreceptors in breast cancer tissue, ${ }^{143-145}$ however, clinical evidence is lacking. To this effect, a prospective randomized controlled trial that exposed the postoperative serum of breast cancer patients who received dexmedetomidine to $\mathrm{MCF}-7$ cells observed significantly elevated MCF-7 cell proliferation, migration, and invasion compared with preoperative serum. ${ }^{144}$ This indicates that in patients undergoing primary breast cancer surgery, perioperative use of dexmedetomidine may influence the serum milieu in a way that encourages the malignancy of breast cancer cells.

Regardless, dexmedetomidine has shown several beneficial effects in its application in tumor surgery. Its administration provides effective cardio-cerebral protection during colorectal cancer surgery, ${ }^{146}$ reduces morphine consumption, delays time to first analgesic supplementation, and decreases pain intensity postoperatively in major abdominal cancer surgery, ${ }^{147}$ and attenuates immunosuppression in patients undergoing radical and reconstructive oral cancer surgery. ${ }^{148}$ Dexmedetomidine could effectively decrease the expression levels of postoperative serum inflammatory factors (including TNF- $\alpha$, IL-6) in patients undergoing gastric cancer surgery, enhance postoperative cognitive function by regulating the PI3K-Akt signaling pathway, and promote recovery of postoperative cognitive function. ${ }^{149}$ Its application in tumor surgery in children including in abdominal malignancy ${ }^{150}$ shows improved postoperative analgesia with better overall analgesia compared with other agents such as fentanyl. The surgical application and consequent effects of dexmedetomidine are summarized in Figure 3.

\section{Comparative Studies with Other Agents}

The efficacy of dexmedetomidine has been compared to similar agents in several studies (Table 2). For example, 


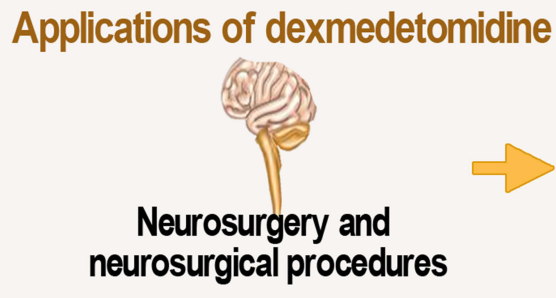

Dexmedetomidine

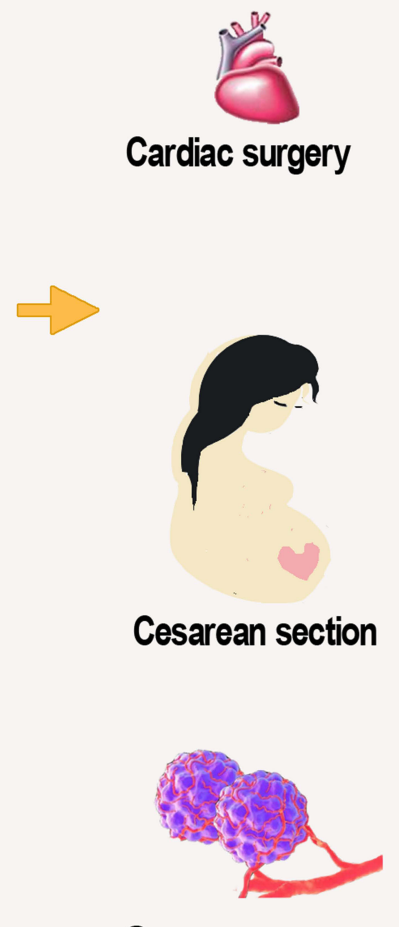

Cancer surgery
Affects of dexmedetomidine

a. Safe and effective neuroprotection

b. Reduces delirium

c. Modest effects on the brain's electrophysiological properties

a. Reduced time of stay in ICU

b. Reduced delirium

c. Reduced risks of abnormal hemodynamics

d. Reduced sevoflurane requirement

e. Decreased surgical stress

a. Lowered intensity and incidence of shivering

b. Reduced anesthetic agent requirement

c. Prolonged duration of analgesia/ optimizes analgesia

d. Kidney protection in preeclampsia

e. Enhanced patient recovery quality and comfort

f. Enhanced lactation

a. Attenuated immunosuppression

b. Effective cardio-cerebral protection

c. Enhanced postoperative cognitive function

d. Improved postoperative analgesia

e. Reduced morphine consumption

Figure 3 The application of dexmedetomidine in some major surgical procedures. The figure presents a summary of desirable effects exhibited by dexmedetomidine in some selected surgical procedures.

an efficacy study of intrathecal dexmedetomidine and fentanyl in reducing visceral pain during an abdominal hysterectomy performed under spinal anesthesia showed better performance of dexmedetomidine as an intrathecal adjuvant. Compared to fentanyl, dexmedetomidine minimized visceral pain and prolonged postoperative analgesia. ${ }^{151}$ Similarly, dexmedetomidine as local anesthetics adjuvant in spinal anesthesia prolonged the duration of spinal anesthesia, improved postoperative analgesia, reduced the incidence of pruritus and did not increase the incidence of hypotension and bradycardia compared to fentanyl. ${ }^{152}$ Another report indicated that during general anesthesia for cesarean section, although remifentanil demonstrated better control of hemodynamic stability, dexmedetomidine rather demonstrated better neonatal Apgar scores, postoperative analgesia, and decreased catecholamine release. ${ }^{139}$ However, other studies have reported no significant difference in the effect of dexmedetomidine and remifentanil on maternal hemodynamics and bi-spectral index, and neonatal outcomes in elective cesarean delivery, although remifentanil still has the potential to cause neonatal transient respiratory depression. ${ }^{153}$

In patients undergoing total knee arthroplasty under spinal anesthesia, intraoperative dexmedetomidine sedation was found to be associated with a small but clinically significant reduction in postoperative opioid use compared to propofol. ${ }^{154}$ The addition of dexmedetomidine and fentanyl to intrathecal bupivacaine improves postoperative 
Table 2 Comparative Studies of Dexmedetomidine and Other Drugs

\begin{tabular}{|c|c|c|c|c|}
\hline $\begin{array}{l}\text { Comparative } \\
\text { Agents }\end{array}$ & $\begin{array}{l}\text { Type of } \\
\text { Study }\end{array}$ & Purpose & Outcome & Reference \\
\hline $\begin{array}{l}\text { Dexmedetomidine vs } \\
\text { propofol }\end{array}$ & $\begin{array}{l}\text { Meta-analysis } \\
\text { of } \\
\text { randomized } \\
\text { controlled } \\
\text { trials }\end{array}$ & $\begin{array}{l}\text { Compare the effect on delirium in } \\
\text { patients after cardiac surgery }\end{array}$ & $\begin{array}{l}\text { Dexmedetomidine reduces postoperative } \\
\text { delirium with a shorter length of intubation but } \\
\text { might increase bradycardia after cardiac surgery } \\
\text { compared with propofol }\end{array}$ & [132] \\
\hline $\begin{array}{l}\text { Midazolam alone or in } \\
\text { combination with } \\
\text { dexmedetomidine or } \\
\text { clonidine }\end{array}$ & $\begin{array}{l}\text { Prospective } \\
\text { double-blind } \\
\text { randomized } \\
\text { study }\end{array}$ & $\begin{array}{l}\text { Compare their efficacy in providing } \\
\text { optimal intubating conditions and } \\
\text { hemodynamic stability }\end{array}$ & $\begin{array}{l}\text { Patients who receive } \alpha 2 \text { agonists are calmer, } \\
\text { cooperative, had less pain and discomfort than } \\
\text { midazolam. Dexmedetomidine allows better } \\
\text { endurance, stable hemodynamics, and patent } \\
\text { airway as compared to clonidine. }\end{array}$ & [122] \\
\hline $\begin{array}{l}\text { Dexmedetomidine vs } \\
\text { fentanyl }\end{array}$ & $\begin{array}{l}\text { Randomized } \\
\text { controlled } \\
\text { trial }\end{array}$ & $\begin{array}{l}\text { Application in spinal anesthesia for } \\
\text { abdominal hysterectomy }\end{array}$ & $\begin{array}{l}\text { Dexmedetomidine performs better than fentanyl } \\
\text { in minimizing visceral pain and prolonging post- } \\
\text { operative analgesia. }\end{array}$ & {$[151]$} \\
\hline $\begin{array}{l}\text { Dexmedetomidine vs } \\
\text { propofol }\end{array}$ & $\begin{array}{l}\text { Phase I clinical } \\
\text { trial }\end{array}$ & $\begin{array}{l}\text { Study of brain functional } \\
\text { connectivity during sleep }\end{array}$ & $\begin{array}{l}\text { There is the rapid recovery of oriented } \\
\text { responsiveness to external stimulation under } \\
\text { dexmedetomidine sedation compared to } \\
\text { propofol }\end{array}$ & [157] \\
\hline $\begin{array}{l}\text { Dexmedetomidine vs } \\
\text { fentanyl }\end{array}$ & $\begin{array}{l}\text { Systematic } \\
\text { review and } \\
\text { meta-analysis }\end{array}$ & $\begin{array}{l}\text { Compare effects as adjuvants to } \\
\text { local anesthetics in spinal } \\
\text { anesthesia }\end{array}$ & $\begin{array}{l}\text { Dexmedetomidine performs better by prolonging } \\
\text { the duration of spinal anesthesia, improving } \\
\text { postoperative analgesia, reducing the incidence of } \\
\text { pruritus, and not increasing the incidence of } \\
\text { hypotension and bradycardia. }\end{array}$ & [152] \\
\hline $\begin{array}{l}\text { Dexmedetomidine vs } \\
\text { propofol }\end{array}$ & $\begin{array}{l}\text { Randomized } \\
\text { controlled } \\
\text { trial }\end{array}$ & $\begin{array}{l}\text { Compare the effect on delirium } \\
\text { after cardiac surgery }\end{array}$ & $\begin{array}{l}\text { Dexmedetomidine reduces incidence, delays } \\
\text { onset, and shortens the duration of } \\
\text { postoperative delirium }\end{array}$ & {$[|3|]$} \\
\hline $\begin{array}{l}\text { Dexmedetomidine vs } \\
\text { remifentanil }\end{array}$ & $\begin{array}{l}\text { Randomized } \\
\text { controlled } \\
\text { trial }\end{array}$ & $\begin{array}{l}\text { Compare the effects on mothers } \\
\text { and neonates during cesarean } \\
\text { section under general anesthesia }\end{array}$ & $\begin{array}{l}\text { Remifentanil was better in controlling } \\
\text { hemodynamic stability, but dexmedetomidine was } \\
\text { better in neonatal Apgar scores, postoperative } \\
\text { analgesia, and decreasing catecholamine release }\end{array}$ & [139] \\
\hline $\begin{array}{l}\text { Dexmedetomidine vs } \\
\text { remifentanil }\end{array}$ & $\begin{array}{l}\text { Comparative } \\
\text { study }\end{array}$ & $\begin{array}{l}\text { Evaluate the effects on maternal } \\
\text { and neonatal outcomes in elective } \\
\text { cesarean delivery }\end{array}$ & $\begin{array}{l}\text { Both drugs are effective to blunt hemodynamic } \\
\text { responses to intubation and also seem safe for } \\
\text { neonates, but remifentanil still has the potential } \\
\text { to cause neonatal transient respiratory } \\
\text { depression. }\end{array}$ & [153] \\
\hline $\begin{array}{l}\text { Dexmedetomidine vs } \\
\text { propofol }\end{array}$ & $\begin{array}{l}\text { Randomized } \\
\text { Trial }\end{array}$ & $\begin{array}{l}\text { To assess which will lower } \\
\text { postoperative opioid analgesic } \\
\text { consumption after total knee } \\
\text { arthroplasty }\end{array}$ & $\begin{array}{l}\text { Dexmedetomidine sedation is associated with a } \\
\text { small but clinically important reduction in } \\
\text { postoperative opioid use }\end{array}$ & [154] \\
\hline $\begin{array}{l}\text { Dexmedetomidine vs } \\
\text { fentanyl }\end{array}$ & $\begin{array}{l}\text { Randomized } \\
\text { controlled } \\
\text { trial }\end{array}$ & $\begin{array}{l}\text { Compare as adjuvants to neuraxial } \\
\text { anesthesia in children experiencing } \\
\text { surgery for abdominal malignancy. }\end{array}$ & $\begin{array}{l}\text { Dexmedetomidine has a better overall analgesia } \\
\text { outcome compared to fentanyl }\end{array}$ & [150] \\
\hline
\end{tabular}

analgesia following abdominal surgery for cancer in children, with better overall analgesia of dexmedetomidine compared with fentanyl. ${ }^{150}$
In neurological procedures including DBS surgery, the use of dexmedetomidine has proven more advantageous over propofol and benzodiazepines. Although careful 
titration of the benzodiazepines or propofol might also elicit a state of anxiolysis or light sedation in which the patient remains responsive, these GABAergic medications strongly interfere with clinical signs such as tremor, even at low doses. Moreover, they impede the firing rate of neurons, leading to interference with MERs, which might raise the threshold of stimulation and interfere with macrostimulation. ${ }^{155-157}$ Awake fiberoptic intubation is the gold standard technique for managing patients with an anticipated difficult airway. In such situations, conscious sedation is desirable not only to make the procedure more tolerable and comfortable for the patient but also to ensure optimal intubating conditions. A study reported that patients who receive $\alpha 2$-adrenoceptor agonists are calmer and cooperative with less pain and discomfort during awake fiberoptic intubation than those who received midazolam. Moreover, dexmedetomidine allows stable hemodynamics, better endurance, and patent airway as compared to clonidine. ${ }^{122}$

\section{Discussion}

Dexmedetomidine possesses potent sedative and anxiolytic properties and is known for its analgesic potential due to a reduction of sympathetic tone. It produces a dosedependent effect, ranging from minimal to deep sedation. Over the past few years, the pharmacokinetic and pharmacodynamic properties of dexmedetomidine have been extensively studied within and beyond the scope of the currently approved indications, and are gaining increasing popularity and application. Current studies report its promising effects as an anti-inflammatory agent, a new class of sleep-enhancing medication, and an enhancer of bowel recovery and relief of sore throat. It has shown admirable safety and efficacy in both surgical and non-surgical procedural sedation in adults and the young. Several comparative studies involving dexmedetomidine and other agents including opioids (fentanyl, morphine, and sufentanil), $\alpha 2$ adrenergic agonists (clonidine), midazolam, neostigmine, magnesium sulfate, and ketamine, mostly report favorable effects of dexmedetomidine. For instance, recent reports indicate that dexmedetomidine is a promising alternative to classic sedatives for procedural sedation compared to agents such as midazolam, as it demonstrates higher patient and operator satisfaction with the patient experience of less pain, lower analgesic requirements, and easy reusability.

In the intensive care unit, sedation is meant to reduce patient discomfort, metabolic demands during organ failure, and increase tolerance towards mechanical ventilation. Clinical practice guidelines for the sustained use of sedatives and analgesics in the critically ill, like the one proposed by Barr and colleagues, ${ }^{158}$ stipulate that the management of pain, agitation, and delirium in intensive care patients require light sedation, except for patients with acute respiratory distress syndrome or brain injury and intracranial hypertension (who rather require deep sedation). There is evidence that deep sedation in the first 48 hours after initiation of mechanical ventilation is associated with elevated long-term mortality. Interestingly, the feasibility and safety of light to mild sedation with dexmedetomidine has been demonstrated, in addition to its being a first-line drug for sedation in the intensive care unit. As compared to midazolam and propofol, dexmedetomidine is associated with a 48-hour reduction in the length of intensive care unit stay and duration of mechanical ventilation, as well as decreased incidence of delirium. Regardless of the stable hemodynamic profile produced by dexmedetomidine in both non-surgical and surgical procedures, it could also result in hemodynamic alteration-associated side effects such as hypertension or hypotension, and bradycardia owing to pre-and post-synaptic $\alpha 2$-receptor stimulation, which causes vasodilatation or vasoconstriction and reflex bradycardia.

Effective acute pain management has considerably evolved in recent years and is a primary area of focus in the quest to reduce the opioid epidemic. Persistent postsurgical pain has an incidence of $30-50 \%$ and negatively influences the quality of life with a significant negative burden on individuals, families, and society. Dexmedetomidine possesses analgesic properties and exhibits different pharmacological mechanisms of action when compared with opioids and other analgesics. It has been demonstrated to evoke a better pain response and hemodynamic stability compared to ropivacaine. There is also evidence of intraoperative dexmedetomidine during general anesthesia improving pain outcome during the first 24 postoperative hours compared to remifentanil. Its use during nerve blocks causes decreased postoperative pain and as an adjuvant during epidural anesthetic presents anesthetic sparing effects. Moreover, dexmedetomidine has beneficial effects of reducing intraoperative opioid consumption and enhancing postoperative sleep quality.

Postoperative cognitive dysfunction, a condition characterized by neurocognitive deficits after surgical procedures, could persist for weeks or months after the stimulating event. Like postoperative delirium, intensive 
care-related delirium and post-intensive care cognitive dysfunction, are likely part of the spectrum of neurocognitive defects that mostly occur after general critical illness (mostly in people with vascular disease, diabetes, atrial fibrillation, heart failure, pre-existing cognitive dysfunction, and the aged). These neurological effects plague patients with several negative outcomes including, increased length of stay at hospitals and higher mortality. Fortunately, increasing evidence indicates that dexmedetomidine can mitigate the incidence of delirium and postoperative cognitive dysfunction. While the role of neuroinflammation has been demonstrated in the pathogenesis of postoperative cognitive dysfunction, the antiinflammatory effect of dexmedetomidine within the central nervous system has also been confirmed. However, available clinical trials appear to present conflicting evidence, in addition to the varying application of neurocognitive instruments and the differences in time endpoints used in measuring clinical outcomes. Regardless, a number of clinical trials demonstrate that dexmedetomidine reduces the incidence of postoperative delirium, a condition strongly associated with a higher occurrence of postoperative cognitive dysfunction. These preliminary pieces of evidence warrant further large-scale clinical trials to further assess the value of dexmedetomidine in this area and related conditions.

Spinal anesthesia is a standard technique for all anesthesiologists and surgeons and is commonly applied in procedures such as cesarean section and other lower body procedures. It is easy to operate, has little influence on the body's physiological functions, permits the patient to remain awake during surgery, and excludes the risks of general anesthesia. Nonetheless, a number of adverse events including hypotension, bradycardia, shivering, nausea, and vomiting are associated with spinal anesthesia and could lead to further complications. For example, the occurrence of nausea and vomiting during operations could cause the contents of the stomach to be mistakenly inhaled into the lungs, resulting in life-threatening pneumonia. Interestingly, there is evidence of improved safety of spinal anesthesia by the use of dexmedetomidine as adjuvant anesthesia, causing the reduced incidence of these adverse events. In addition, it can shorten the onset time of local anesthesia and prolong the block duration time without increasing the drug-related side effects. In addition to dexmedetomidine, many other drugs can be administered as adjuncts for local anesthetics to enhance the efficacy and quality of spinal anesthesia. Comparative studies of dexmedetomidine and these drugs mostly indicate promising advantages of dexmedetomidine. For example, dexmedetomidine prolongs the duration of spinal anesthesia, improves postoperative analgesia, reduces the incidence of pruritus, and does not increase the incidence of hypotension and bradycardia compared to fentanyl.

\section{Conclusion}

Dexmedetomidine is a useful and attractive drug, with great potential in many clinical situations. In addition to its known primary pharmacological effects, recent studies report other effects such as a new class of sleep-enhancing medication, bowel recovery, relief of sore throat, as well as anti-inflammation. Although recent research indicates admirable advances in its clinical value and application with promising potentials, it is still limited, hence further studies are required. There is the need to explore the optimum condition, including dosage and route of administration, at which postoperative or intraoperative dexmedetomidine can exhibit maximum anti-inflammatory, bowel recovery, sleep enhancing, and sore throat relieving effects. The pharmacological effects and associated adverse events of dexmedetomidine should also be well understood by physicians and anesthesiologists before its application. Moreover, careful selection of patients and determination of the appropriate dosage are crucial steps in the application of dexmedetomidine to ensure patient safety. In the phase of the conflicting outcomes of available trials (which are mostly small-scale), there is the need for high-quality, large sample, randomized controlled trials to verify the effects and safety of dexmedetomidine.

\section{Disclosure}

The authors declare no conflicts of interest in this work.

\section{References}

1. Tasbihgou SR, Barends CRM, Absalom AR. The role of dexmedetomidine in neurosurgery. Best Pract Res Clin Anaesthesiol. 2021;35 (2):221-229. doi:10.1016/j.bpa.2020.10.002

2. Wang G, Niu J, Li Z, Lv H, Cai H. The efficacy and safety of dexmedetomidine in cardiac surgery patients: a systematic review and meta-analysis. PLoS One. 2018;13(9):e0202620. doi:10.1371/journal.pone. 0202620

3. Constantin J-M, Momon A, Mantz J, et al. Efficacy and safety of sedation with dexmedetomidine in critical care patients: a meta-analysis of randomized controlled trials. Anaesth Crit Care Pain Med. 2016;35(1):7-15. doi:10.1016/j.accpm.2015.06.012

4. Mahmoud M, Mason KP. Dexmedetomidine: review, update, and future considerations of paediatric perioperative and periprocedural applications and limitations. Br J Anaesth. 2015;115(2):171-182. doi:10.1093/bja/aev226 
5. Afonso J, Reis F. Dexmedetomidine: current role in anesthesia and intensive care. Brazilian J Anesthesiol. 2012;62(1):118-133. doi:10.1016/S0034-7094(12)70110-1

6. Weerink MAS, Struys MMRF, Hannivoort LN, Barends CRM, Absalom AR, Colin P. Clinical Pharmacokinetics and Pharmacodynamics of Dexmedetomidine. Clin Pharmacokinet. 2017;56(8):893-913. doi:10.1007/s40262-017-0507-7

7. Ihmsen H, Saari TI. Dexmedetomidine. Anaesthesist. 2012;61 (12):1059-1066. doi:10.1007/s00101-012-2114-1

8. Duan X, Coburn M, Rossaint R, Sanders RD, Waesberghe JV, Kowark A. Efficacy of perioperative dexmedetomidine on postoperative delirium: systematic review and meta-analysis with trial sequential analysis of randomised controlled trials. Br J Anaesth. 2018;121(2):384-397. doi:10.1016/j.bja.2018.04.046

9. Pan H, Liu C, Ma X, Xu Y, Zhang M, Wang Y. Perioperative dexmedetomidine reduces delirium in elderly patients after noncardiac surgery: a systematic review and meta-analysis of randomized-controlled trials. Can J Anesth Can D'anesthésie. 2019;66 (12):1489-1500. doi:10.1007/s12630-019-01440-6

10. Chamadia S, Pedemonte JC, Hobbs LE, et al. A pharmacokinetic and pharmacodynamic study of oral dexmedetomidine. Anesthesiology. 2020;133(6):1223-1233. doi:10.1097/ALN.00 00000000003568

11. Su F, Gastonguay MR, Nicolson SC, DiLiberto M, OcampoPelland A, Zuppa AF. Dexmedetomidine pharmacology in neonates and infants after open heart surgery. Anesth Analg. 2016;122(5):1556-1566. doi:10.1213/ANE.0000000000000869

12. Li A, Yuen VM, Goulay-Dufaÿ S, et al. Pharmacokinetic and pharmacodynamic study of intranasal and intravenous dexmedetomidine. Br J Anaesth. 2018;120(5):960-968. doi:10.1016/j. bja.2017.11.100

13. Keating GM. Dexmedetomidine: a review of its use for sedation in the intensive care setting. Drugs. 2015;75(10):1119-1130. doi:10.1007/s40265-015-0419-5

14. Turunen H, Jakob SM, Ruokonen E, et al. Dexmedetomidine versus standard care sedation with propofol or midazolam in intensive care: an economic evaluation. Crit Care. 2015;19 (1):67. doi:10.1186/s13054-015-0787-y

15. Jakob SM. Dexmedetomidine vs midazolam or propofol for sedation during prolonged mechanical ventilation. JAMA. 2012;307 (11):1151. doi:10.1001/jama.2012.304

16. Xia Z-Q, Chen S-Q, Yao X, Xie C-B, Wen S-H, Liu K-X. Clinical benefits of dexmedetomidine versus propofol in adult intensive care unit patients: a meta-analysis of randomized clinical trials. $J$ Surg Res. 2013;185(2):833-843. doi:10.1016/j.jss.2013.06.062

17. Su X, Meng Z-T, Wu X-H, et al. Dexmedetomidine for prevention of delirium in elderly patients after non-cardiac surgery: a randomised, double-blind, placebo-controlled trial. Lancet. 2016;388(10054):1893-1902. doi:10.1016/S0140-6736(16)30 580-3

18. Cioccari L, Luethi N, Bailey M, et al. The effect of dexmedetomidine on vasopressor requirements in patients with septic shock: a subgroup analysis of the Sedation Practice in Intensive Care Evaluation [SPICE III] Trial. Crit Care. 2020;24(1):441. doi:10.1186/s13054-020-03115-x

19. Dersch-Mills DA, Banasch HL, Yusuf K, Howlett A. Dexmedetomidine use in a tertiary care NICU: a descriptive study. Ann Pharmacother. 2019;53(5):464-470. doi:10.1177/ 1060028018812089

20. Mondardini MC, Sperotto F, Daverio M, et al. Efficacy and safety of dexmedetomidine for prevention of withdrawal syndrome in the pediatric intensive care unit: protocol for an adaptive, multicenter, randomized, double-blind, placebo-controlled, non-profit clinical trial. Trials. 2019;20(1):710. doi:10.1186/s13063-0193793-6
21. Wang L, Huang L, Zhang T, Peng W. Comparison of intranasal dexmedetomidine and oral midazolam for premedication in pediatric dental patients under general anesthesia: a randomised clinical trial. Biomed Res Int. 2020;2020:1-7.

22. Sottas CE, Anderson BJ. Dexmedetomidine: the new all-in-one drug in paediatric anaesthesia? Curr Opin Anaesthesiol. 2017;30 (4):441-451. doi:10.1097/ACO.0000000000000488

23. Mason KP, Kelhoffer ER, Prescilla R, et al. Feasibility of measuring memory response to increasing dexmedetomidine sedation in children. Br J Anaesth. 2017;118(2):254-263. doi:10.1093/bja/ aew421

24. Bailey CR. Dexmedetomidine in children - when should we be using it? Anaesthesia. 2021;76(3):309-311. doi:10.1111/an ae. 15169

25. Mason KP, Lerman J. Dexmedetomidine in children. Anesth Analg. 2011;113(5):1129-1142. doi:10.1213/ANE.0b01 $3 \mathrm{e} 31822 \mathrm{~b} 8629$

26. Sinha R, Kumar KR. Intravenous dexmedetomidine augments the oculocardiac reflex. J Am Assoc Pediatr Ophthalmol Strabismus. 2019;23(1):62. doi:10.1016/j.jaapos.2018.09.001

27. Shah P, Dubey K, Sahare K, Agrawal A. Intravenous dexmedetomidine versus propofol for intraoperative moderate sedation during spinal anesthesia: a comparative study. J Anaesthesiol Clin Pharmacol. 2016;32(2):245. doi:10.4103/0970-9185.168172

28. He L, Xu J-M, Liu S-M, Chen Z-J, Li X, Zhu R. Intrathecal dexmedetomidine alleviates shivering during cesarean delivery under spinal anesthesia. Biol Pharm Bull. 2017;40(2):169-173. doi:10.1248/bpb.b16-00651

29. Lamontagne C, Lesage S, Villeneuve E, Lidzborski E, Derstenfeld A, Crochetière C. Intravenous dexmedetomidine for the treatment of shivering during Cesarean delivery under neuraxial anesthesia: a randomized-controlled trial. Can J Anesth Can D'anesthésie. 2019;66(7):762-771. doi:10.1007/s12630-01901354-3

30. Gambling DR. Intravenous dexmedetomidine. Int $J$ Obstet Anesth. 2019;39:148. doi:10.1016/j.ijoa.2019.02.004

31. Paramasivan A, Lopez-Olivo MA, Foong TW, Tan YW, Yap APA. Intrathecal dexmedetomidine and postoperative pain: a systematic review and meta-analysis of randomized controlled trials. Eur J Pain. 2020;24(7):1215-1227. doi:10.1002/ejp.1575

32. Xia F, Chang X, Zhang Y, Wang L, Xiao F. The effect of intrathecal dexmedetomidine on the dose requirement of hyperbaric bupivacaine in spinal anaesthesia for caesarean section: a prospective, double-blinded, randomized study. BMC Anesthesiol. 2018;18(1):74. doi:10.1186/s12871-018-0528-2

33. Sharma A, Varghese N, Venkateswaran R. Effect of intrathecal dexmedetomidine versus intravenous dexmedetomidine on subarachnoid anesthesia with hyperbaric bupivacaine. $J$ Anaesthesiol Clin Pharmacol. 2020;36(3):381. doi:10.4103/joacp.JOA CP_323_17

34. Li BL, Zhang N, Huang JX, et al. A comparison of intranasal dexmedetomidine for sedation in children administered either by atomiser or by drops. Anaesthesia. 2016;71(5):522-528. doi:10.1111/anae.13407

35. Yuen VM, Hui TW, Irwin MG, Yao T-J, Wong GL, Yuen MK. Optimal timing for the administration of intranasal dexmedetomidine for premedication in children. Anaesthesia. 2010;65(9):922929. doi:10.1111/j.1365-2044.2010.06453.x

36. Xie Z, Shen W, Lin J, Xiao L, Liao M, Gan X. Sedation effects of intranasal dexmedetomidine delivered as sprays versus drops on pediatric response to venous cannulation. Am J Emerg Med. 2017;35(8):1126-1130. doi:10.1016/j.ajem.2017.03.021

37. Chamadia S, Hobbs L, Marota S, et al. Oral dexmedetomidine promotes non-rapid eye movement Stage 2 sleep in humans. Anesthesiology. 2020;133(6):1234-1243. doi:10.1097/ ALN.0000000000003567 
38. Sajid B, Mohamed T, Jumaila M. A comparison of oral dexmedetomidine and oral midazolam as premedicants in children. $J$ Anaesthesiol Clin Pharmacol. 2018;35(1):36-40. doi:10.4103/ joacp.JOACP_20_18

39. Keles S, Kocaturk O. Comparison of oral dexmedetomidine and midazolam for premedication and emergence delirium in children after dental procedures under general anesthesia: a retrospective study. Drug Des Devel Ther. 2018;12:647-653. doi:10.2147/ DDDT.S163828

40. Barends CRM, Absalom A, van Minnen B, Vissink A, Visser A. Dexmedetomidine versus Midazolam in Procedural Sedation. A Systematic Review of Efficacy and Safety. PLoS One. 2017;12 (1):e0169525. doi:10.1371/journal.pone.0169525

41. Prabhu M, Mehandale S. Comparison of oral dexmedetomidine versus oral midazolam as premedication to prevent emergence agitation after sevoflurane anaesthesia in paediatric patients. Indian J Anaesth. 2017;61(2):131. doi:10.4103/0019-5049.1 99852

42. Mason KP, Lubisch NB, Robinson F, Roskos R. Intramuscular Dexmedetomidine Sedation for Pediatric MRI and CT. Am J Roentgenol. 2011;197(3):720-725. doi:10.2214/AJR.10.6134

43. Ruan X. Low-Dose Intramuscular Dexmedetomidine as Premedication: a Randomized Controlled Trial. Med Sci Monit. 2014;20:2714-2719. doi:10.12659/MSM.891051

44. Scheinin H, Jaakola M-L, Sjövall S, et al. Intramuscular Dexmedetomidine as Premedication for General Anesthesia. Anesthesiology. 1993;78(6):1065-1075. doi:10.1097/00000542199306000-00008

45. Joo E, Kim YJ, Park Y, et al. Intramuscular dexmedetomidine and oral chloral hydrate for pediatric sedation for electroencephalography: a propensity score-matched analysis. Pediatr Anesth. 2020;30(5):584-591. doi:10.1111/pan.13844

46. Carlone G, Trombetta A, Amoroso S, Poropat F, Barbi E, Cozzi G. Intramuscular Dexmedetomidine, a Feasible Option for Children With Autism Spectrum Disorders Needing Urgent Procedural Sedation. Pediatr Emerg Care. 2019;35(6):e116e117. doi:10.1097/PEC.0000000000001776

47. Misra S, Behera BK, Mitra JK, Sahoo AK, Jena SS, Srinivasan A. Effect of preoperative dexmedetomidine nebulization on the hemodynamic response to laryngoscopy and intubation: a randomized control trial. Korean J Anesthesiol. 2021;74(2):150-157. doi: $10.4097 / \mathrm{kja} .20153$

48. Kumar NR, Jonnavithula N, Padhy S, Sanapala V, Naik V. Evaluation of nebulised dexmedetomidine in blunting haemodynamic response to intubation: a prospective randomised study. Indian J Anaesth. 2020;64(10):874. doi:10.4103/ija.IJA_235_20

49. Zhang H, Sha J, Feng $X$, et al. Dexmedetomidine ameliorates LPS induced acute lung injury via GSK-3 $\beta / \mathrm{STAT} 3-\mathrm{NF}-\kappa \mathrm{B}$ signaling pathway in rats. Int Immunopharmacol. 2019;74:105717. doi:10.1016/j.intimp.2019.105717

50. Meng L, Li L, Lu S, et al. The protective effect of dexmedetomidine on LPS-induced acute lung injury through the HMGB1mediated TLR4/NF- $\mathrm{KB}$ and PI3K/Akt/mTOR pathways. Mol Immunol. 2018;94:7-17. doi:10.1016/j.molimm.2017.12.008

51. Li J, Zhao Y, Zhou N, Li L, Li K. Dexmedetomidine Attenuates Myocardial Ischemia-Reperfusion Injury in Diabetes Mellitus by Inhibiting Endoplasmic Reticulum Stress. $J$ Diabetes Res. 2019;2019:1-12.

52. Liang S, Wang Y, Liu Y. Dexmedetomidine alleviates lung ischemia-reperfusion injury in rats by activating PI3K/Akt pathway. Eur Rev Med Pharmacol Sci. 2019;23(1):370-377. doi:10.26355/ eurrev_201901_16785

53. Chen $\bar{Y}$, Bian $\mathrm{W}, \mathrm{Xu}$ B. Pretreatment with dexmedetomidine alleviates lung injury in a rat model of intestinal ischemia reperfusion. Mol Med Rep. 2020;21(3):1233-1241. doi:10.3892/ mmr.2020.10942
54. Chen Y, Miao L, Yao Y, et al. Dexmedetomidine Ameliorate CLP-Induced Rat Intestinal Injury via Inhibition of Inflammation. Mediators Inflamm. 2015;2015:1-9. doi:10.1155/ 2015/289519

55. Koca U, Olguner CG, Ergür BU, et al. The effects of dexmedetomidine on secondary acute lung and kidney injuries in the rat model of intra-abdominal sepsis. Sci World J. 2013;2013:1-11.

56. Zhang J-R, Lin Q, Liang F-Q, Xie T. Dexmedetomidine attenuates lung injury by promoting mitochondrial fission and oxygen consumption. Med Sci Monit. 2019;25:1848-1856. doi:10.12659/ MSM.913239

57. Sun Y-B, Zhao H, Mu D-L, et al. Dexmedetomidine inhibits astrocyte pyroptosis and subsequently protects the brain in in vitro and in vivo models of sepsis. Cell Death Dis. 2019;10 (3):167. doi:10.1038/s41419-019-1416-5

58. Wu J, Vogel T, Gao X, Lin B, Kulwin C, Chen J. Neuroprotective effect of dexmedetomidine in a murine model of traumatic brain injury. Sci Rep. 2018;8(1):4935. doi:10.1038/s41598-018-23003-3

59. Gao J, Sun Z, Xiao Z, et al. Dexmedetomidine modulates neuroinflammation and improves outcome via alpha2-adrenergic receptor signaling after rat spinal cord injury. $\mathrm{Br} J$ Anaesth. 2019;123(6):827-838. doi:10.1016/j.bja.2019.08.026

60. Dardalas I, Stamoula E, Rigopoulos P, et al. Dexmedetomidine effects in different experimental sepsis in vivo models. Eur $J$ Pharmacol. 2019;856:172401. doi:10.1016/j.ejphar.2019.05.030

61. Yu Q, Zou L, Yuan X, Fang F, Xu F. Dexmedetomidine protects against septic liver injury by enhancing autophagy through activation of the AMPK/SIRT1 signaling pathway. Front Pharmacol. 2021;12:658677. doi:10.3389/fphar.2021.658677

62. Wang $\mathrm{C}$, Yuan $\mathrm{W}, \mathrm{Hu} \mathrm{A}$, et al. Dexmedetomidine alleviated sepsis-induced myocardial ferroptosis and septic heart injury. Mol Med Rep. 2020;22(1):175-184. doi:10.3892/mmr.2020.11114

63. Kang K, Gao Y, Wang S-C, et al. Dexmedetomidine protects against lipopolysaccharide-induced sepsis-associated acute kidney injury via an $\alpha 7$ nAChR-dependent pathway. Biomed Pharmacother. 2018;106:210-216. doi:10.1016/j.biopha.201 8.06.059

64. Shi J, Yu T, Song K, et al. Dexmedetomidine ameliorates endotoxin-induced acute lung injury in vivo and in vitro by preserving mitochondrial dynamic equilibrium through the HIF-1a/HO-1 signaling pathway. Redox Biol. 2021;41:101954. doi:10.1016/j. redox.2021.101954

65. Fu C, Dai X, Yang Y, Lin M, Cai Y, Cai S. Dexmedetomidine attenuates lipopolysaccharide-induced acute lung injury by inhibiting oxidative stress, mitochondrial dysfunction and apoptosis in rats. Mol Med Rep. 2017;15(1):131-138. doi:10.3892/ mmr.2016.6012

66. Zhang J, Xia F, Zhao H, et al. Dexmedetomidine-induced cardioprotection is mediated by inhibition of high mobility group box1 and the cholinergic anti-inflammatory pathway in myocardial ischemia-reperfusion injury. PLoS One. 2019;14(7):e0218726. doi:10.1371/journal.pone.0218726

67. Chang J-H, Jin -M-M, Liu J-T. Dexmedetomidine pretreatment protects the heart against apoptosis in ischemia/reperfusion injury in diabetic rats by activating PI3K/Akt signaling in vivo and in vitro. Biomed Pharmacother. 2020;127:110188. doi:10.1016/j. biopha.2020.110188

68. Zhang J, Peng K, Zhang J, Meng X, Ji F. Dexmedetomidine preconditioning may attenuate myocardial ischemia/reperfusion injury by down-regulating the HMGB1-TLR4-MyD88-NF-кB signaling pathway. PLoS One. 2017;12(2):e0172006. doi:10.1371/journal.pone.0172006

69. Yang Y, Wang H, Song N, et al. Dexmedetomidine attenuates ischemia/reperfusion-induced myocardial inflammation and apoptosis through inhibiting endoplasmic reticulum stress signaling. $J$ Inflamm Res. 2021;14:1217-1233. doi:10.2147/JIR.S292263 
70. Zhang Y, Gao Q, Wu Z, Xue H, Liu B, Zhao P. Dexmedetomidine promotes hippocampal neurogenesis and improves spatial learning and memory in neonatal rats. Drug Des Devel Ther. 2020;13:4439-4449. doi:10.2147/DDDT.S228220

71. Tachibana K, Hashimoto T, Kato R, et al. Neonatal administration with dexmedetomidine does not impair the rat hippocampal synaptic plasticity later in adulthood. Pediatr Anesth. 2012;22 (7):713-719. doi:10.1111/j.1460-9592.2012.03810.x

72. Lv K, Yang C, Xiao R, et al. Dexmedetomidine attenuates ethanol-induced inhibition of hippocampal neurogenesis in neonatal mice. Toxicol Appl Pharmacol. 2020;390:114881. doi:10.1016/j. taap.2020.114881

73. Li J, Chen Q, He X, et al. Dexmedetomidine attenuates lung apoptosis induced by renal ischemia-reperfusion injury through a2AR/PI3K/Akt pathway. $J$ Transl Med. 2018;16(1):78. doi:10.1186/s12967-018-1455-1

74. Yu T, Liu D, Gao M, et al. Dexmedetomidine prevents septic myocardial dysfunction in rats via activation of $\alpha 7 \mathrm{nAChR}$ and PI3K/Akt- mediated autophagy. Biomed Pharmacother. 2019;120:109231. doi:10.1016/j.biopha.2019.109231

75. Elmorsy SA, Soliman GF, Rashed LA, Elgendy $H$. Dexmedetomidine and propofol sedation requirements in an autistic rat model. Korean J Anesthesiol. 2019;72(2):169-177. doi:10.4097/kja.d.18.00005

76. Chang Y-F, Chao A, Shih P-Y, et al. Comparison of dexmedetomidine versus propofol on hemodynamics in surgical critically ill patients. J Surg Res. 2018;228:194-200. doi:10.1016/j. jss.2018.03.040

77. Jun JH, Kim KN, Kim JY, Song SM. The effects of intranasal dexmedetomidine premedication in children: a systematic review and meta-analysis. Can J Anesth Can D'anesthésie. 2017;64 (9):947-961. doi:10.1007/s12630-017-0917-x

78. Yang X, Hu Z, Peng F, et al. Effects of Dexmedetomidine on Emergence Agitation and Recovery Quality Among Children Undergoing Surgery Under General Anesthesia: a MetaAnalysis of Randomized Controlled Trials. Front Pediatr. 2020;8:580226. doi:10.3389/fped.2020.580226

79. Zhu M, Wang H, Zhu A, Niu K, Wang G. Meta-Analysis of Dexmedetomidine on Emergence Agitation and Recovery Profiles in Children after Sevoflurane Anesthesia: different Administration and Different Dosage. PLoS One. 2015;10(4): e0123728. doi:10.1371/journal.pone. 0123728

80. Zhang J, Yu Y, Miao S, et al. Effects of peri-operative intravenous administration of dexmedetomidine on emergence agitation after general anesthesia in adults: a meta-analysis of randomized controlled trials. Drug Des Devel Ther. 2019;13:2853-2864. doi:10.2147/DDDT.S207016

81. Vorobeichik L, Brull R, Abdallah FW. Evidence basis for using perineural dexmedetomidine to enhance the quality of brachial plexus nerve blocks: a systematic review and meta-analysis of randomized controlled trials. Br J Anaesth. 2017;118(2):167-181. doi:10.1093/bja/aew411

82. Emelife PI, Eng MR, Menard BL, et al. Adjunct medications for peripheral and neuraxial anesthesia. Best Pract Res Clin Anaesthesiol. 2018;32(2):83-99. doi:10.1016/j.bpa.2018.06.011

83. Trifa M, Tumin D, Tobias JD. Dexmedetomidine as an adjunct for caudal anesthesia and analgesia in children. Minerva Anestesiol. 2018;84(7):836-847. doi:10.23736/S0375-9393.18.12523-5

84. Bielka K, Kuchyn I, Babych V, Martycshenko K, Inozemtsev O. Dexmedetomidine infusion as an analgesic adjuvant during laparoscopic cholecystectomy: a randomized controlled study. $B M C$ Anesthesiol. 2018;18(1):44. doi:10.1186/s12871-018-0508-6

85. Kaye AD, Chernobylsky DJ, Thakur P, et al. Dexmedetomidine in Enhanced Recovery After Surgery (ERAS) Protocols for Postoperative Pain. Curr Pain Headache Rep. 2020;24(5):21. doi:10.1007/s11916-020-00853-z
86. Mao Y, Sun X, Si L, et al. Perioperative Dexmedetomidine Fails to Improve Postoperative Analgesic Consumption and Postoperative Recovery in Patients Undergoing Lateral Thoracotomy for Thoracic Esophageal Cancer: a Randomized, Double-Blind, Placebo-Controlled Trial. Pain Res Manag. 2020;2020:1-12. doi:10.1155/2020/4145893

87. Grape S, Kirkham KR, Frauenknecht J, Albrecht E. Intra-operative analgesia with remifentanil vs. dexmedetomidine: a systematic review and meta-analysis with trial sequential analysis. Anaesthesia. 2019;74(6):793-800. doi:10.1111/anae.14657

88. Peng K, Zhang J, Meng X-W, Liu H-Y, Ji F-H. Optimization of Postoperative Intravenous Patient-Controlled Analgesia with Opioid-Dexmedetomidine Combinations: an Updated MetaAnalysis with Trial Sequential Analysis of Randomized Controlled Trials. Pain Physician. 2017;20(7):569-596.

89. Beloeil H, Garot M, Lebuffe G, et al. Balanced Opioid-free Anesthesia with Dexmedetomidine versus Balanced Anesthesia with Remifentanil for Major or Intermediate Noncardiac Surgery. Anesthesiology. 2021;134(4):541-551. doi:10.1097/ALN.000 0000000003725

90. Li R, Lai IK, Pan JZ, Zhang P, Maze M. Dexmedetomidine Exerts an Anti-inflammatory Effect via $\alpha 2$ Adrenoceptors to Prevent Lipopolysaccharide-induced Cognitive Decline in Mice. Anesthesiology. 2020;133(2):393-407. doi:10.1097/ALN.000000 0000003390

91. Ma J, Chen Q, Li J, et al. Dexmedetomidine-Mediated Prevention of Renal Ischemia-Reperfusion Injury Depends in Part on Cholinergic Anti-Inflammatory Mechanisms. Anesth Analg. 2020;130(4):1054-1062. doi:10.1213/ANE.0000000000003820

92. Chen X, Li L, Hu J, et al. Anti-inflammatory effect of dexmedetomidine combined with hypothermia on acute respiratory distress syndrome in rats. J Surg Res. 2017;216:179-184. doi:10.1016/j. jss.2017.05.014

93. Ueki M, Kawasaki T, Habe K, Hamada K, Kawasaki C, Sata T. The effects of dexmedetomidine on inflammatory mediators after cardiopulmonary bypass. Anaesthesia. 2014;69(7):693-700. doi:10.1111/anae.12636

94. Flanders CA, Rocke AS, Edwardson SA, Baillie JK, Walsh TS. The effect of dexmedetomidine and clonidine on the inflammatory response in critical illness: a systematic review of animal and human studies. Crit Care. 2019;23(1):402. doi:10.1186/s13054019-2690-4

95. Zhou H, Lu J, Shen Y, Kang S, Zong Y. Effects of dexmedetomidine on CD42a + /CD14 +, HLADR + /CD14 + and inflammatory cytokine levels in patients undergoing multilevel spinal fusion. Clin Neurol Neurosurg. 2017;160:54-58. doi:10.1016/j. clineuro.2017.06.012

96. Xiang H, Hu B, Li Z, Li J. Dexmedetomidine Controls Systemic Cytokine Levels through the Cholinergic Anti-inflammatory Pathway. Inflammation. 2014;37(5):1763-1770. doi:10.1007/ s10753-014-9906-1

97. Kim Y, Kang S-H, Hong T-H, et al. Effects of dexmedetomidine on the ratio of $\mathrm{T}$ Helper 1 to $\mathrm{T}$ Helper 2 cytokines in patients undergoing laparoscopic cholecystectomy. J Clin Anesth. 2014;26 (4):281-285. doi:10.1016/j.jclinane.2013.11.018

98. Lee J-M, Han H-J, Choi W-K, Yoo S, Baek S, Lee J. Immunomodulatory effects of intraoperative dexmedetomidine on $\mathrm{T}$ helper $1, \mathrm{~T}$ helper 2 , $\mathrm{T}$ helper 17 and regulatory $\mathrm{T}$ cells cytokine levels and their balance: a prospective, randomised, double-blind, dose-response clinical study. BMC Anesthesiol. 2018;18(1):164. doi:10.1186/s12871-018-0625-2

99. Qiu Z, Lu P, Wang K, et al. Dexmedetomidine Inhibits Neuroinflammation by Altering Microglial M1/M2 Polarization Through MAPK/ERK Pathway. Neurochem Res. 2020;45(2):345353. doi:10.1007/s11064-019-02922-1 
100. Sun $\mathrm{Z}$, Lin $\mathrm{Y}$, Li $\mathrm{Y}$, et al. The effect of dexmedetomidine on inflammatory inhibition and microglial polarization in BV-2 cells. Neurol Res. 2018;40(10):838-846. doi:10.1080/01616412.20 18.1493849

101. Zhang X, Wang J, Qian W, et al. Dexmedetomidine inhibits inducible nitric oxide synthase in lipopolysaccharide-stimulated microglia by suppression of extracellular signal-regulated kinase. Neurol Res. 2015;37(3):238-245. doi:10.1179/1743132814Y.0 000000426

102. Akeju O, Hobbs LE, Gao L, et al. Dexmedetomidine promotes biomimetic non-rapid eye movement stage 3 sleep in humans: a pilot study. Clin Neurophysiol. 2018;129(1):69-78. doi:10.1016/j. clinph.2017.10.005

103. Huang X, Lin D, Sun Y, Wu A, Wei C. Effect of Dexmedetomidine on Postoperative Sleep Quality: a Systematic Review. Drug Des Devel Ther. 2021;15:2161-2170. doi:10.2147/ DDDT.S304162

104. An J-X, Williams JP, Fang Q-W, et al. Feasibility of PatientControlled Sleep with Dexmedetomidine in Treating Chronic Intractable Insomnia. Nat Sci Sleep. 2020;12:1033-1042. doi:10.2147/NSS.S262991

105. Bk B, Misra S, Ss J, Cr M. The effect of perioperative dexmedetomidine on postoperative bowel function recovery in adult patients receiving general anaesthesia: a systematic review and meta-analysis of randomised controlled trials. Minerva Anestesiol. 2021. doi:10.23736/S0375-9393.21.15773-6

106. Huang -S-S, Song F-X, Yang S-Z, et al. Impact of intravenous dexmedetomidine on postoperative bowel movement recovery after laparoscopic nephrectomy: a consort-prospective, randomized, controlled trial. World J Clin Cases. 2021;9(26):77627771. doi:10.12998/wjcc.v9.i26.7762

107. Xu S-Q, Li Y-H, Wang S-B, Hu S-H, Ju X, Xiao J-B. Effects of intravenous lidocaine, dexmedetomidine and their combination on postoperative pain and bowel function recovery after abdominal hysterectomy. Minerva Anestesiol. 2017;83(7)::685-694. doi:10.23736/S0375-9393.16.11472-5

108. Liu Y, Ai D, Wang X. Efficacy of perioperative intravenous dexmedetomidine administration for the prevention of postoperative sore throat: a meta-analysis. J Int Med Res. 2021;49 (5):030006052110176. doi:10.1177/03000605211017686

109. Kuriyama A, Maeda H. Preoperative intravenous dexamethasone prevents tracheal intubation-related sore throat in adult surgical patients: a systematic review and meta-analysis. Can J Anesth Can D'anesthésie. 2019;66(5):562-575. doi:10.1007/s12630-01801288-2

110. Kim H, Kwon H, Jeon S, Choi EK. The effect of dexmedetomidine and remifentanil on the postoperative sore throat after thyroidectomy. Medicine. 2020;99(29):e21060. doi:10.1097/ MD.0000000000021060

111. Thomas D, Chacko L, Raphael P. Dexmedetomidine nebulisation attenuates post-operative sore throat in patients undergoing thyroidectomy: a randomised, double-blind, comparative study with nebulised ketamine. Indian $J$ Anaesth. 2020;64(10):863. doi:10.4103/ija.IJA 40620

112. Bekker A, Sturaitis MK. Dexmedetomidine for Neurological Surgery. Oper Neurosurg. 2005;57:1-10. doi:10.1227/01. NEU.0000163476.42034.A1

113. Kogan M, McGuire M, Riley J. Deep Brain Stimulation for Parkinson Disease. Neurosurg Clin N Am. 2019;30(2):137-146. doi:10.1016/j.nec.2019.01.001

114. Formolo DA, Gaspar JM, Melo HM, et al. Deep Brain Stimulation for Obesity: a Review and Future Directions. Front Neurosci. 2019;13:323. doi:10.3389/fnins.2019.00323

115. Tierney TS. Deep brain stimulation foundations and future trends. Front Biosci. 2018;23(1):4586. doi:10.2741/4586
116. Husch A, Petersen MV, Gemmar P, Goncalves J, Sunde N, Hertel F. Post-operative deep brain stimulation assessment: automatic data integration and report generation. Brain Stimul. 2018;11 (4):863-866. doi:10.1016/j.brs.2018.01.031

117. Lee WH, Park C-K, Park H-P, et al. Effect of Dexmedetomidine Combined Anesthesia on Motor evoked Potentials During Brain Tumor Surgery. World Neurosurg. 2019;123:e280-e287. doi:10.1016/j.wneu.2018.11.152

118. Chen Z, Lin S, Shao W. Effects on somatosensory and motor evoked potentials of senile patients using different doses of dexmedetomidine during spine surgery. Irish J Med Sci. 2015;184 (4):813-818. doi:10.1007/s11845-014-1178-0

119. Morace R, De Angelis M, Aglialoro E, et al. Sedation with $\alpha 2$ Agonist Dexmedetomidine During Unilateral Subthalamic Nucleus Deep Brain Stimulation: a Preliminary Report. World Neurosurg. 2016;89:320-328. doi:10.1016/j.wneu.2016.01.037

120. Raimann F, Adam E, Strouhal U, Zacharowski K, Seifert V, Forster M-T. Dexmedetomidine as adjunct in awake craniotomy - improvement or not? Anaesthesiol Intensive Ther. 2020;52 (1):15-22. doi:10.5114/ait.2020.93043

121. McAuliffe N, Nicholson S, Rigamonti A, et al. Awake craniotomy using dexmedetomidine and scalp blocks: a retrospective cohort study. Can J Anesth Can D'anesthésie. 2018;65(10):1129-1137. doi:10.1007/s12630-018-1178-z

122. Bano N, Singh P, Singh D, Prabhakar T. A comparative study of midazolam alone or in combination with dexmedetomidine or clonidine for awake fiberoptic intubation. Anesth Essays Res. 2019;13(3):539. doi:10.4103/aer.AER 6419

123. El Mourad MB, Elghamry MR, Mansour RF, Afandy ME. Comparison of Intravenous Dexmedetomidine-Propofol Versus Ketofol for Sedation During Awake Fiberoptic Intubation: a Prospective, Randomized Study. Anesthesiol Pain Med. 2019;9 (1):e86442.

124. Garavaglia MM, Das S, Cusimano MD, et al. Anesthetic Approach to High-Risk Patients and Prolonged Awake Craniotomy Using Dexmedetomidine and Scalp Block. J Neurosurg Anesthesiol. 2014;26(3):226-233. doi:10.1097/ ANA.0b013e3182a58aba

125. Mahajan C, Rath G, Singh G, Mishra N, Sokhal S, Bithal P. Efficacy and safety of dexmedetomidine infusion for patients undergoing awake craniotomy: an observational study. Saudi J Anaesth. 2018;12(2):235. doi:10.4103/sja.SJA_608_17

126. Prontera A, Baroni S, Marudi A, et al. Awake craniotomy anesthetic management using dexmedetomidine, propofol, and remifentanil. Drug Des Devel Ther. 2017;11:593-598. doi:10.2147/ DDDT.S124736

127. Mirkheshti A, Memary E, Honar BN, Jalaeefar A, Sezari P. The efficacy of local dexmedetomidine during fiberoptic nasotracheal intubation: a randomized clinical trial. $J$ Anaesthesiol Clin Pharmacol. 2017;33(2):209-214. doi:10.4103/joacp.JOACP_2 4216

128. Dhasmana SC. Nasotracheal Fiberoptic Intubation: patient Comfort, Intubating Conditions and Hemodynamic Stability During Conscious Sedation with Different Doses of Dexmedetomidine. J Maxillofac Oral Surg. 2014;13(1):53-58. doi:10.1007/s12663-012-0469-0

129. Balachundhar S, Puja S, Shahzad S, et al. Effect of Intravenous Acetaminophen vs Placebo Combined With Propofol or Dexmedetomidine on Postoperative Delirium Among Older Patients Following Cardiac Surgery: the DEXACET Randomized Clinical Trial. JAMA. 2019;322(3):276.

130. Sun Y, Liu J, Yuan X, Li Y. Effects of dexmedetomidine on emergence delirium in pediatric cardiac surgery. Minerva Pediatr. 2017;69(3):165-173. doi:10.23736/S0026-4946.16. 04227-4 
131. Djaiani G, Silverton N, Fedorko L, et al. Dexmedetomidine versus Propofol Sedation Reduces Delirium after Cardiac Surgery. Anesthesiology. 2016;124(2):362-368. doi:10.1097/ ALN.0000000000000951

132. Liu X, Xie G, Zhang K, et al. Dexmedetomidine vs propofol sedation reduces delirium in patients after cardiac surgery: a meta-analysis with trial sequential analysis of randomized controlled trials. J Crit Care. 2017;38:190-196. doi:10.1016/j. jcrc.2016.10.026

133. Turan A, Duncan A, Leung S, et al. Dexmedetomidine for reduction of atrial fibrillation and delirium after cardiac surgery (DECADE): a randomised placebo-controlled trial. Lancet. 2020;396(10245):177-185. doi:10.1016/S0140-6736(20)30631-0

134. Momeni M, Khalifa C, Lemaire G, et al. Propofol plus low-dose dexmedetomidine infusion and postoperative delirium in older patients undergoing cardiac surgery. Br J Anaesth. 2021;126 (3):665-673. doi:10.1016/j.bja.2020.10.041

135. Tang Y, Yang M, Fu F, Huang X, Feng Y, Chen X. Comparison of the ED50 of intrathecal hyperbaric ropivacaine co-administered with or without intrathecal dexmedetomidine for cesarean section: a prospective, double-blinded, randomized dose-response trial using up-down sequential allocation method. J Clin Anesth. 2020;62:109725. doi:10.1016/j.jclinane.2020.109725

136. Liu L, Qian J, Shen B, Xiao F, Shen H. Intrathecal dexmedetomidine can decrease the $95 \%$ effective dose of bupivacaine in spinal anesthesia for cesarean section. Medicine. 2019;98(9): e14666. doi:10.1097/MD.0000000000014666

137. Nasseri K, Ghadami N, Nouri B. Effects of intrathecal dexmedetomidine on shivering after spinal anesthesia for cesarean section: a double-blind randomized clinical trial. Drug Des Devel Ther. 2017;11:1107-1113. doi:10.2147/DDDT.S131866

138. Zhang Q, Wang L, Xu M, Wang T. Protective effect of dexmedetomidine on kidney injury of parturients with preeclampsia undergoing cesarean section: a randomized controlled study. Biosci Rep. 2019;39:5.

139. Yu Z, Zhang P, Wang H, et al. Effects of dexmedetomidine versus remifentanil on mothers and neonates during cesarean section under general anesthesia. Biomed Pap. 2020;164(4):417-424. doi:10.5507/bp.2019.055

140. Wang Y, Fang X, Liu C, Ma X, Song Y, Yan M. Impact of Intraoperative Infusion and Postoperative PCIA of Dexmedetomidine on Early Breastfeeding After Elective Cesarean Section: a Randomized Double-Blind Controlled Trial. Drug Des Devel Ther. 2020;14:1083-1093. doi:10.2147/DDDT. S241153

141. Pérez-González O, Cuéllar-Guzmán LF, Soliz J, Cata JP. Impact of Regional Anesthesia on Recurrence, Metastasis, and Immune Response in Breast Cancer Surgery. Reg Anesth Pain Med. 2017;42(6):751-756. doi:10.1097/AAP.0000000000000662

142. Sessler DI, Riedel B. Anesthesia and Cancer Recurrence. Anesthesiology. 2019;130(1):3-5. doi:10.1097/ALN.00000 00000002506

143. Rivero EM, Martinez LM, Bruque CD, Gargiulo L, Bruzzone A, Lüthy IA. Prognostic significance of $\alpha$ - and $\beta 2$-adrenoceptor gene expression in breast cancer patients. $\mathrm{Br} J$ Clin Pharmacol. 2019;85(9):2143-2154. doi:10.1111/bcp.14030

144. Liu Y, Sun J, Wu T, et al. Effects of serum from breast cancer surgery patients receiving perioperative dexmedetomidine on breast cancer cell malignancy: a prospective randomized controlled trial. Cancer Med. 2019;8(18):7603-7612. doi:10.1002/ cam4.2654
145. Lamkin DM, Sung HY, Yang GS, et al. $\alpha 2$-Adrenergic blockade mimics the enhancing effect of chronic stress on breast cancer progression. Psychoneuroendocrinology. 2015;51:262-270. doi:10.1016/j.psyneuen.2014.10.004

146. Yi X-L, Wang J-T, Chu C-Q, Li Y-X, Yin J-H, Liu S-L. Cardiocerebral protective effects of dexmedetomidine as anesthetic in colorectal cancer surgery. Eur Rev Med Pharmacol Sci. 2018;22(11):3570-3576. doi:10.26355/eurrev_201806_15183

147. Hetta D, Fares KM, Abedalmohsen AM, Abdel-Wahab AH, Abo Elfadl GM, Ali WN. Epidural dexmedetomidine infusion for perioperative analgesia in patients undergoing abdominal cancer surgery: randomized trial. J Pain Res. 2018;11:2675-2685. doi:10.2147/JPR.S163975

148. Huang L, Qin C, Wang L, Zhang T, Li J. Effects of dexmedetomidine on immune response in patients undergoing radical and reconstructive surgery for oral cancer. Oncol Lett. 2020;21 (2):106. doi:10.3892/ol.2020.12367

149. Wang Z, Shen Z, Wang H, Zhang L, Dong R. Effect of dexmedetomidine on the cognitive function of patients undergoing gastric cancer surgery by regulating the PI3K/AKT signaling pathway. Oncol Lett. 2020;19(2):1151-1156. doi:10.3892/ ol.2019.11224

150. Fares KM, Mohamed SA-B, Abd El-Rahman AM, AbdeLemam RM, Osman AMM. Analgesic effect of intrathecal fentanyl vs dexmedetomidine as adjuvants to bupivacaine following abdominal surgery for cancer in children, a randomized trial. Pain Med. 2020;21(11):2634-2641. doi:10.1093/pm/pnaa259

151. Gautam B, Tabdar S, Shrestha U. Comparison of fentanyl and dexmedetomidine as intrathecal adjuvants to spinal anaesthesia for abdominal hysterectomy. JNMA J Nepal Med Assoc. 2018;56 (213):848-855. doi:10.31729/jnma.3739

152. Sun S, Wang J, Bao N, Chen Y, Wang J. Comparison of dexmedetomidine and fentanyl as local anesthetic adjuvants in spinal anesthesia: a systematic review and meta-analysis of randomized controlled trials. Drug Des Devel Ther. 2017;11:3413-3424. doi:10.2147/DDDT.S146092

153. Li C, Li Y, Wang K, Kong X. Comparative evaluation of remifentanil and dexmedetomidine in general anesthesia for cesarean delivery. Med Sci Monit. 2015;21:3806-3813. doi:10.12659/ MSM.895209

154. Shin H-J, Do S-H, Lee J-S, Kim T-K, Na H-S. Comparison of intraoperative sedation with dexmedetomidine versus propofol on acute postoperative pain in total knee arthroplasty under spinal anesthesia. Anesth Analg. 2019;129(6):1512-1518. doi:10.1213/ ANE.0000000000003315

155. Venkatraghavan L, Luciano M, Manninen P. Anesthetic management of patients undergoing deep brain stimulator insertion. Anesth Analg. 2010;1:587.

156. Grant R, Gruenbaum SE, Gerrard J. Anaesthesia for deep brain stimulation. Curr Opin Anaesthesiol. 2015;28(5):505-510. doi:10.1097/ACO.0000000000000230

157. Guldenmund P, Vanhaudenhuyse A, Sanders RD, et al. Brain functional connectivity differentiates dexmedetomidine from propofol and natural sleep. Br J Anaesth. 2017;119(4):674-684. doi:10.1093/bja/aex257

158. Barr J, Fraser GL, Puntillo K, et al. Clinical practice guidelines for the management of pain, agitation, and delirium in adult patients in the intensive care unit. Crit Care Med. 2013;41 (1):263-306. doi:10.1097/CCM.0b013e3182783b72 


\section{Publish your work in this journal}

The Journal of Inflammation Research is an international, peerreviewed open-access journal that welcomes laboratory and clinical findings on the molecular basis, cell biology and pharmacology of inflammation including original research, reviews, symposium reports, hypothesis formation and commentaries on: acute/chronic inflammation; mediators of inflammation; cellular processes; molecular mechanisms; pharmacology and novel anti-inflammatory drugs; clinical conditions involving inflammation. The manuscript management system is completely online and includes a very quick and fair peerreview system. Visit http://www.dovepress.com/testimonials.php to read real quotes from published authors. 